NBER WORKING PAPER SERIES

\title{
THE SOCIAL SECURITY TRUST FUND, THE RISKLESS INTEREST RATE, AND CAPITAL ACCUMULATION
}

\author{
Andrew B. Abel
}

Working Paper 6991

http://www.nber.org/papers/w6991

\section{NATIONAL BUREAU OF ECONOMIC RESEARCH \\ 1050 Massachusetts Avenue \\ Cambridge, MA 02138 \\ March 1999}

Prepared for NBER Conference on Risk Aspects of Investment-Based Social Security Reform, January 15-16, 1999. I thank Henning Bohn, John Campbell, Bill Dupor, Robert King, Deborah Lucas, Amir Yaron, and participants in the NBER Pre-Conference and Conference for helpful comments. I also thank Farshad Mashayekhi for excellent research asssitance. The views expressed in this paper are those of the authors and do not reflect those of the National Bureau of Economic Research.

( 1999 by Andrew B. Abel. All rights reserved. Short sections of text, not to exceed two paragraphs, may be quoted without explicit permission provided that full credit, including ${ }^{\circledR}$ notice, is given to the source. 
The Social Security Trust Fund, the Riskless

Interest Rate, and Capital Accumulation

Andrew B. Abel

NBER Working Paper No. 6991

March 1999

JEL No. E6, H3

\begin{abstract}
This paper develops a tractable stochastic overlapping generations model to analyze the equilibrium equity premium and growth rate of the capital stock in the presence of a defined-benefit Social Security system. If the Social Security Trust Fund increases the share of its portfolio held in risky capital, the equilibrium equity premium falls in the following period and along a constant growth path. This change in the portfolio of the Social Security Trust Fund will increase the growth rate of capital in the following period, and, if a certain sufficient condition is satisfied, will increase the growth rate of the capital stock along a constant growth path. Calibration of the model indicates that it can match the historical average equity premium and the historical average growth rate of the capital stock using plausible values of the preference parameters. In addition, the sufficient condition for the growth rate of the capital stock to increase along a constant growth path is satisfied. Quantitatively, the effects on the riskless interest rate and the growth rate of capital are small.
\end{abstract}

\author{
Andrew B. Abel \\ Department of Finance \\ The Wharton School of the University of Pennsylvania \\ 3620 Locust Walk \\ Philadelphia, PA 19104-6367 \\ and NBER \\ abel@wharton.upenn.edu
}


The Social Security Trust Fund in the United States currently has about three quarters of a trillion dollars in assets. Its assets are projected to grow to almost 2 trillion 1998 dollars in the year 2016. As the baby-boom generation begins to retire and collect Social Security benefits in the second decade of the twenty-first century, the Social Security Trust Fund will shrink, and it is projected to run out of assets in the year 2032. ${ }^{1}$ The prospect that the Social Security system will run large deficits and exhaust the Social Security Trust Fund has given rise to a variety of proposals to "save Social Security." Some proposals are designed to exploit the equity premium, which is the excess of the rate of return on equity over the riskless interest rate. Since the equity premium has historically averaged several hundred basis points per year, it may be tempting to shift some of the assets of the Social Security Trust Fund (which currently holds only bonds) from bonds to equity. In this paper I analyze the effects on the equilibrium equity premium and the equilibrium growth rate of the capital stock of such a portfolio change.

I have three goals in this paper. First, I want to develop a tractable stochastic dynamic general equilibrium model of Social Security and national capital accumulation with an endogenous equity premium. Second, although tractability dictates that the model is relatively simple, I want to calibrate the model numerically and would like the calibrated model to be quantitatively plausible in some dimensions. In particular, I would like the model to be able to match the historical average equity premium and the historical average growth rate of capital. Third, I want to apply the model to analyze the effects on the equity premium and the growth rate of capital of investing some of the Social Security Trust Fund in risky capital.

A natural starting point for a model of Social Security and capital accumulation is Diamond's (1965) classic model of government debt in a neoclassical economy, which has been applied to analyze the effects of Social Security on national capital accumulation in a deterministic context. ${ }^{2}$ In order to achieve the goals of this paper, I modify the Diamond model in two important ways. First, because the Diamond model is a deterministic model, the equity premium is identically zero in that model. Since I want

\footnotetext{
${ }^{1}$ Table III.B2 of the 1998 Annual Report of the Board of Trustees of the Federal OldAge and Survivors Insurance and Disability Insurance Trust Funds reports projections for the assets of the combined OASI and DI Trust Funds. The yearend projections based on intermediate cost assumptions in constant (1998) dollars are $\$ 756.9$ billion for 1998 and $\$ 1,960.4$ billion for 2016 .

${ }^{2}$ For a textbook example, see Blanchard and Fischer, (1989), pp. 110-113.
} 
to model the equilibrium equity premium, I introduce risk so that a positive average equity premium is a feature of equilibrium. Second, to help keep the analysis tractable, I replace the neoclassical production function with an " $A K$ " model that is consistent with endogenous growth. I introduce risk in the model by assuming that productivity is stochastic.

I model four sets of economic actors-firms, individuals, the Treasury, and the Social Security system-and I describe the behavior of each of these sets of economic actors in the first four analytic sections of the paper. The behavior of firms is presented in Section 1 where I present the stochastic $A K$ technology and then derive the equilibrium wage and risky return on capital. With a stochastic $A K$ technology, the rate of return on capital is stochastic, but exogenous. The stochastic nature of the rate of return on capital allows for a positive equity premium in equilibrium. The exogenous nature of this risky rate of return keeps the model tractable. Although the risky rate of return is exogenous in this model, the riskless interest rate is endogenous, so the equity premium is also endogenous. Any change in the riskless interest rate is matched by a change in the equity premium of the same magnitude but in the opposite direction. Thus, I will focus attention on the behavior of the equilibrium riskless interest rate, recognizing that the results directly translate into results about the equity premium.

The consumption/saving and portfolio decisions of individuals are analyzed in Section 2. My choice of a specification of the utility function reflects the tension between analytic tractability and quantitative realism. To achieve analytic tractability, I assume that the utility function is characterized by an intertemporal elasticity of substitution equal to one, as is the case, for example, with logarithmic utility. However, with logarithmic utility the coefficient of relative of risk aversion also equals one, and quantitative realism dictates a coefficient of relative risk aversion greater than one. Thus, I use a special case of the preferences introduced by Epstein and Zin (1989) and Weil (1990) to allow for a coefficient of relative risk aversion greater than one and an intertemporal elasticity of substitution equal to one.

Although the behavior of firms and individuals is based on explicit maximization, I do not attempt to specify the objective functions of the Treasury and the Social Security system and then derive optimal policy. Instead I specify policy functions for each of these fiscal institutions in Sections 3 and 4. To prevent the amount of Treasury debt from becoming too large or too small in the face of stochastic shocks, I assume that the Treasury adjusts taxes and government purchases in response to deviations of the debt-GDP 
ratio from a target value. As for the Social Security system, I examine a pay-as-you-go defined-benefit system, and allow Social Security taxes to adjust when the ratio of the Social Security Trust Fund to the aggregate capital stock deviates from its target value. In addition, I assume that the Social Security Trust Fund can choose how to allocate its portfolio to riskless bonds and risky capital.

Firms, individuals, the Treasury, and the Social Security system interact in capital markets to determine the riskless interest rate (and hence the equity premium) and the growth rate of the aggregate capital stock. This model has a convenient recursive structure. The riskless interest rate is determined by portfolio allocation decisions of individuals and does not depend on the aggregate level of the capital stock. Then, given the value of the riskless interest rate, the saving decisions of individuals determine the growth rate of the capital stock. The presentation of results in Section 5 reflects this recursive structure.

I examine the riskless interest rate in subsection 5.1. An increase in the amount of riskless bonds relative to the amount of capital causes the riskless interest rate to increase (equivalently, the equity premium to fall) because individuals must be induced to hold a higher share of riskless assets in their portfolios. In particular, if the Social Security Trust Fund sells some bonds to the public in exchange for risky capital, then in the context of a pay-asyou-go defined-benefit system, the real interest rate must increase to induce individuals to increase the share of riskless assets in their portfolios.

After analyzing the equilibrium riskless interest rate in subsection 5.1, I analyze the equilibrium value of the growth rate of the capital stock in subsection 5.2. The growth rate of the capital stock is determined by the amount of saving in the economy. I show that if the Social Security Trust Fund sells some bonds in exchange for risky capital, the capital stock in the following period will be higher than if the Social Security Trust Fund held only bonds. This effect arises because the change in the portfolio of the Social Security Trust Fund causes the riskless interest rate to increase, which reduces the present value of the Social Security benefits that current workers expect when they retire. In response to this reduction in the present value of lifetime income, current workers reduce their consumption and increase their saving. The effect on the saving of future generations involves additional effects operating through the adjustment of taxes to satisfy the budget constraints and policy functions of the Treasury and Social Security system. I focus my analysis of saving by future generations by considering constant 
growth paths which I define and analyze in subsection 5.2.1. Proposition 6 in this subsection presents a sufficient condition for the growth rate of the capital stock along a constant growth path to increase when the share of the Social Security Trust Fund invested in risky capital increases.

I explore the quantitative plausibility of the model in section 6 where I show that the endogenous riskless interest rate and growth rate of capital along a constant growth path can match the historical average values of these variables for reasonable values of the preference parameters. I also explore the sensitivity of these endogenous variables to various parameters and calibrated values of variables. In addition, I show that an increase in the share of the Social Security Trust Fund that is invested in risky capital will increase the growth rate of capital along a constant growth path because the sufficient condition in Proposition 6 is satisfied in the baseline calibration and in the sensitivity analysis. Quantitatively, the model suggests that investing a modest fraction of the Social Security Trust Fund in risky capital will have only small effects on the riskless interest rate and the growth rate of the capital stock.

I present concluding remarks in Section 7. Various technical derivations are relegated to Appendices A through E.

\section{Factor Prices in General Equilibrium}

The economy consists of overlapping generations of people who live for two periods. At the beginning of period $t$, a continuum of people with measure $N_{t}$ is born. Each of these people inelastically supplies one unit of labor when young in period $t$, and does not supply any labor when old in period $t+1$.

Output in period $t$ is produced using labor and capital. In period $t$, firm $i$ uses labor, $N_{i, t}$, and capital, $K_{i, t}$, to produce output, $Y_{i, t}$, according to the production function

$$
Y_{i, t}=A_{t} K_{i, t}^{\alpha}\left(N_{i, t} K_{t}\right)^{1-\alpha}
$$

where $^{3} A_{t} \geq A_{L}>0$ is an i.i.d. productivity shock with mean $\bar{A}, K_{t}$ is the

\footnotetext{
${ }^{3} A_{L}$ is the greatest lower bound for $A_{t}$. In addition, I assume that there is a positive probability that $A_{t}$ is within a small neighborhood of $A_{L}$. Specifically, $\operatorname{Pr}\left\{A_{t} \geq A_{L}\right\}=1$, and for all $\varepsilon>0, \operatorname{Pr}\left\{A_{L} \leq A_{t} \leq A_{L}+\varepsilon\right\}>0$.
} 
aggregate capital stock at the beginning of period $t$, and $0<\alpha<1$. The production function in equation (1) is consistent with endogenous growth. ${ }^{4}$

Factor prices are determined in competitive markets, and the rental price of each factor equals its marginal product. Thus, the wage rate in period $t$, $w_{t}$, is

$$
w_{t}=(1-\alpha) A_{t}\left(\frac{K_{i, t}}{N_{i, t}}\right)^{\alpha} K_{t}^{1-\alpha}
$$

and the gross rate of return to capital in period $t, R_{t}$, is

$$
R_{t}=\alpha A_{t}\left(\frac{N_{i, t} K_{t}}{K_{i, t}}\right)^{1-\alpha}
$$

In equilibrium, each firm will choose the same capital-labor ratio, so that $\frac{K_{i, t}}{N_{i, t}}=\frac{K_{t}}{N_{t}}$ for all $i$. Now assume that the population is constant over time, adopt the normalization $N_{t} \equiv 1$, and substitute $\frac{K_{i, t}}{N_{i, t}}=K_{t}$ in equations (2) and (3) to obtain

$$
w_{t}=(1-\alpha) A_{t} K_{t}
$$

and

$$
R_{t}=\alpha A_{t}
$$

The gross rate of return on capital is random and has mean $\bar{R}=\alpha \bar{A}$.

\section{Individual Optimization}

Each person faces an optimization problem that includes a saving/consumption decision and a portfolio decision. I will solve the optimization problem of a person born in period $t$ after first specifying the person's budget constraint and then specifying the person's utility function.

A representative person born at the beginning of period $t$ supplies one unit of labor in period $t$ and receives wage income equal to $w_{t}$. Also in period

\footnotetext{
${ }^{4}$ See, for example, Barro and Sala-i-Martin (1995, p. 150).
} 
$t$, the person pays taxes $T_{t}^{T}$ to the Treasury and pays Social Security taxes $T_{t}^{S}$. Both types of taxes are lump-sum. I have distinguished taxes paid to the Treasury from taxes paid to the Social Security system so that I can keep track of the Treasury's outstanding debt and the amount of Treasury bonds held by the Social Security Trust Fund.

A young person in period $t$ has disposable income of $w_{t}-T_{t}^{S}-T_{t}^{T}$ which can be used for consumption and the purchase of riskless bonds and risky capital. Riskless bonds purchased in period $t$ pay a gross rate of return $r_{t+1}$ in period $t+1$. Let $B_{t+1}^{P}$ be the value of riskless bonds purchased by a young person in period $t$ (the superscript $P$ denotes that the bonds are privately held, in contrast to bonds held by the Social Security Trust Fund). The person also purchases risky capital $K_{t+1}^{P}$ which pays a gross rate of return $R_{t+1}$ in period $t+1$. Since consumption when young, $C_{t}$, plus the purchases of bonds and risky capital equals disposable income,

$$
C_{t}=w_{t}-T_{t}^{S}-T_{t}^{T}-B_{t+1}^{P}-K_{t+1}^{P}
$$

Let $X_{t+1}$ be the consumption of an old person in period $t+1$. This consumption is financed by the riskless bonds and risky capital purchased in period $t$ and by Social Security benefits. Riskless bonds are worth $r_{t+1} B_{t+1}^{P}$ and risky capital is worth $R_{t+1} K_{t+1}^{P}$. Social Security benefits consist of two components. One component is $\theta_{1} w_{t+1}=\theta_{1}(1-\alpha) A_{t+1} K_{t+1}$, which is proportional to the actual wage in period $t+1$. The other component is $\theta_{0} \bar{w}_{t+1}$ where $\bar{w}_{t+1}$ is the expected value of $w_{t+1}$ conditional on information available at the end of period $t$. Since the capital stock $K_{t+1}$ is known at the end of period $t, \bar{w}_{t+1}=(1-\alpha) \bar{A} K_{t+1}$. Taking account of both components of the Social Security benefits, the total amount of Social Security benefits, $Q_{t+1}$, received by an old person in period $t+1$ is

$$
Q_{t+1}=\theta_{0}(1-\alpha) \bar{A} K_{t+1}+\theta_{1}(1-\alpha) A_{t+1} K_{t+1}
$$

I assume that $\theta_{0} \geq 0$ and $\theta_{1} \geq 0$. It is convenient, though not strictly accurate, to refer to the parameters $\theta_{0}$ and $\theta_{1}$ as "replacement rates" for Social Security. Because the Social Security benefits received by an old person do not depend on the amount of Social Security taxes paid by that person, nor on any decision made by that person, I describe the system in this model as a defined-benefit system.

The solution of the person's optimization problem is facilitated by using 
equation (5) to rewrite the Social Security benefits in equation (7) as

$$
Q_{t+1}=\theta_{0}(1-\alpha) \bar{A} K_{t+1}+\theta_{1} \frac{1-\alpha}{\alpha} R_{t+1} K_{t+1} .
$$

Because $w_{t+1}$ is perfectly correlated with $R_{t+1}$ in this model, the claim on future Social Security benefits can be viewed as consisting of a riskless asset plus a risky asset with a payoff that is perfectly correlated with the rate of return on risky capital, as illustrated in equation (8).

I assume that individuals do not have a bequest motive and thus they consume all available resources when they are old. Taking account of privatelyheld bonds and risky capital as well as Social Security benefits, $Q_{t+1}$, yields

$$
X_{t+1}=\left(B_{t+1}^{P}+\frac{\theta_{0}(1-\alpha) \bar{A} K_{t+1}}{r_{t+1}}\right) r_{t+1}+\left(K_{t+1}^{P}+\theta_{1} \frac{1-\alpha}{\alpha} K_{t+1}\right) R_{t+1} .
$$

Suppose that each person born at the beginning of period $t$ has the following utility function which is a special case of the parametric class of preferences developed by Epstein and Zin (1989) and Weil (1990) and used by Bohn (1998a) to study intergenerational risk sharing, ${ }^{5,6}$

$$
U_{t}=\ln C_{t}+\frac{\delta}{1-\phi} \ln E_{t}\left\{X_{t+1}^{1-\phi}\right\} \text { where } 0<\phi \neq 1 \text { and } \delta>0
$$

For the utility function in equation (10), the intertemporal elasticity of substitution equals one, and the coefficient of relative risk aversion over second-period consumption is $\phi$. I have chosen to specify a unitary intertemporal elasticity of substitution to simplify the consumption/saving decision and to help keep the general equilibrium analysis tractable. A standard time-separable utility function with a constant coefficient of relative risk aversion constrains the coefficient of relative risk aversion to equal the inverse of intertemporal elasticity of substitution, which equals one in this case. However, I do not constrain the coefficient of relative risk aversion to equal one because various studies of the equity premium puzzle have shown that it is difficult, or perhaps impossible, to account for the large historical average

\footnotetext{
${ }^{5}$ If $\phi=1$, the utility function is $U_{t}=\ln C_{t}+\delta E_{t}\left\{\ln X_{t+1}\right\}$.

${ }^{6}$ Individuals may also obtain utility from government purchases. I assume that any utility from government purchases is additively separable from utility of the consumer's own consumption.
} 
value of the equity premium, $R_{t+1}-r_{t+1}$, with a coefficient of relative risk aversion as low as one.

The optimization problem of a young person in period $t$ is to choose $C_{t}$, $B_{t+1}^{P}$, and $K_{t+1}^{P}$ to maximize the utility function in equation (10) subject to the constraints in equations (6) and (9). The solution to this problem is easily expressed in term of $\Omega_{t}$, the present value of lifetime resources, which is

$$
\Omega_{t} \equiv w_{t}-T_{t}^{T}-T_{t}^{S}+\frac{\theta_{0}(1-\alpha) \bar{A} K_{t+1}}{r_{t+1}}+\theta_{1} \frac{1-\alpha}{\alpha} K_{t+1} .
$$

The present value of lifetime resources consists of disposable income, $w_{t}-$ $T_{t}^{T}-T_{t}^{S}$, plus the present value of the Social Security benefits ${ }^{7}$ to be received in period $t+1, \frac{\theta_{0}(1-\alpha) \bar{A} K_{t+1}}{r_{t+1}}+\theta_{1} \frac{1-\alpha}{\alpha} K_{t+1}$.

Let $a_{t+1}$ be the value of a young person's total assets at the end of period $t$. These assets consist of direct holdings of riskless bonds, $B_{t+1}^{P}$, and risky capital, $K_{t+1}^{P}$, plus the present value of future Social Security benefits, $\frac{\theta_{0}(1-\alpha) \bar{A} K_{t+1}}{r_{t+1}}+\theta_{1} \frac{1-\alpha}{\alpha} K_{t+1}$. Thus,

$$
a_{t+1} \equiv B_{t+1}^{P}+K_{t+1}^{P}+\frac{\theta_{0}(1-\alpha) \bar{A} K_{t+1}}{r_{t+1}}+\theta_{1} \frac{1-\alpha}{\alpha} K_{t+1}
$$

As shown in equation (A.5) in Appendix A, the optimal value of $a_{t+1}$ is

$$
a_{t+1}=\frac{\delta}{1+\delta} \Omega_{t}
$$

To describe the optimal allocation of a young person's portfolio, let $\gamma_{t+1}$ be the share of the total portfolio $a_{t+1}$ devoted to risky assets, consisting of risky capital, $K_{t+1}^{P}$, and the present value of risky future Social Security benefits, $\theta_{1} \frac{1-\alpha}{\alpha} K_{t+1}$. More precisely,

$$
\gamma_{t+1} \equiv \frac{K_{t+1}^{P}+\theta_{1} \frac{1-\alpha}{\alpha} K_{t+1}}{a_{t+1}}
$$

The definitions in equations (12) and (14) imply that $1-\gamma_{t+1}$ is the share of a young consumer's total portfolio devoted to riskless assets, consisting of

\footnotetext{
${ }^{7}$ In computing the present value of future Social Security benefits, the riskless component, $\theta_{0}(1-\alpha) \bar{A} K_{t+1}$, is discounted by the riskless rate $r_{t+1}$, and the risky component, $\theta_{1} \frac{1-\alpha}{\alpha} R_{t+1} K_{t+1}$, is discounted by the risky rate $R_{t+1}$.
} 
riskless bonds, $B_{t+1}^{P}$, and the present value of riskless future Social Security benefits, $\frac{\theta_{0}(1-\alpha) \bar{A} K_{t+1}}{r_{t+1}}$.

Let $\gamma\left(r_{t+1}\right)$ denote the optimal value of $\gamma_{t+1}$. This notation emphasizes that the optimal portfolio allocation depends on the riskless interest rate, $r_{t+1}$, which is an endogenous variable in this model. The optimal portfolio allocation also depends on the distribution of the risky rate of return, $R_{t+1}$, but this distribution is exogenous in this model, so the notation does not reflect this dependence. The optimal value of $\gamma_{t+1}$ is characterized in Appendix B, where it is shown that if $\phi \leq 1$, then $\gamma^{\prime}\left(r_{t+1}\right)<0$. If $\phi>1$, then $\gamma^{\prime}\left(r_{t+1}\right)$ may be negative, zero, or positive. Henceforth, I restrict attention to the case with $\gamma^{\prime}\left(r_{t+1}\right)<0 .{ }^{8}$

The definition of $\gamma_{t+1}$ in equation (14) and the optimal value of $a_{t+1}$ in equation (13) imply the following expressions for optimal holdings of assets by a young person at the end of period $t$

$$
B_{t+1}^{P}+\frac{\theta_{0}(1-\alpha) \bar{A} K_{t+1}}{r_{t+1}}=\left[1-\gamma\left(r_{t+1}\right)\right] \frac{\delta}{1+\delta} \Omega_{t}
$$

and

$$
K_{t+1}^{P}+\theta_{1} \frac{1-\alpha}{\alpha} K_{t+1}=\gamma\left(r_{t+1}\right) \frac{\delta}{1+\delta} \Omega_{t}
$$

The riskless interest rate $r_{t+1}$ affects the private demand for capital in two ways. Since I am restricting attention to the case in which $\gamma^{\prime}\left(r_{t+1}\right)<0$, an increase in the riskless interest $r_{t+1}$ causes consumers to shift their portfolios toward the riskless asset and away from risky assets, thereby reducing the private demand for capital, for a given present value of lifetime resources $\Omega_{t}$. In addition, if $\theta_{0}>0$, an increase in $r_{t+1}$ reduces the present value of riskless Social Security benefits and thus reduces $\Omega_{t}$, as shown in equation (11). This reduction in $\Omega_{t}$ reduces the private demand for capital. Thus, an increase in $r_{t+1}$ reduces the private demand for capital both by changing the composition and (if $\theta_{0}>0$ ) reducing the size of private portfolios.

\footnotetext{
${ }^{8}$ In the calibration in Section 6 , the value of $\phi$ exceeds one so that, in principle, $\gamma^{\prime}\left(r_{t+1}\right)$ can be positive, negative, or zero. For all of the cases examined in Tables 1, 2, and 3, $\gamma^{\prime}\left(r_{t+1}\right)<0$.
} 


\section{The Treasury's Revenues, Expenditures, and Debt}

The Social Security Trust Fund in the United States holds several hundred billion dollars of bonds issued by the Treasury. Because these bonds are liabilities of the Treasury and assets of the Social Security Trust Fund, it is important to treat the Treasury and Social Security system separately. In this section I specify the Treasury's behavior.

The budget constraint of the Treasury is

$$
B_{t+1}=r_{t} B_{t}+G_{t}-T_{t}^{T}
$$

where $B_{t}$ is the amount of Treasury debt outstanding at the end of period $t-1$ (equivalently, the beginning of period $t), r_{t}$ is the gross rate of return on these bonds, $G_{t}$ is the Treasury's expenditure on purchases of consumption goods ${ }^{9}$ during period $t$, and, as in section $2, T_{t}^{T}$ is the tax revenue collected from young consumers by the Treasury during period $t$.

A simple approach to modeling fiscal policy is to assume that government purchases, $G_{t}$, and Treasury taxes, $T_{t}^{T}$, are each proportional to aggregate output, $A_{t} K_{t}$, and then to let the stock of Treasury debt evolve according to equation (17). However, in the face of stochastic shocks to $A_{t}$, the stock of debt could become arbitrarily large or arbitrarily small (indeed negative and large in absolute value). Therefore, I will modify the simple assumptions of proportional government purchases and taxes so that purchases are reduced and/or taxes are increased if the stock of debt is above some target level. Similarly, if the stock of debt is below the target, then purchases are increased and/or taxes are cut.

To measure the size of the Treasury's debt relative to the size of the economy, define $b_{t+1} \equiv \frac{B_{t+1}}{K_{t+1}}$ as the ratio of Treasury debt to the aggregate capital stock. ${ }^{10} \quad$ Let $\beta$ be the "target" value of $b_{t+1}$. I have put the word "target" in quotation marks because the Treasury does not literally aim to set $b_{t+1}$ equal to $\beta$. The Treasury moves the value of $b_{t+1}$ toward $\beta$ according

\footnotetext{
${ }^{9} \mathrm{I}$ assume that all capital formation in the economy is done by the private sector, so that all of the Treasury's expenditure on goods is for consumption goods.

${ }^{10}$ The size of a country's debt is often expressed as a debt-GDP ratio, $\frac{B_{t}}{Y_{t}}$, which is $\frac{B_{t}}{A_{t} K_{t}}$ in this model. The measure I use in this paper is proportional to $\frac{B_{t}}{\bar{A} K_{t}}$ which is the ratio of debt to "trend" GDP, $\bar{A} K_{t}$.
} 
to the following policy function

$$
b_{t+1}-\beta=\rho_{B}\left(b_{t}-\beta\right)+\rho_{A}(g-\tau)\left(A_{t}-\bar{A}\right)
$$

where $\rho_{B} \geq 0$ and $\rho_{A} \geq 0$ are parameters governing the evolution of the debt-capital ratio $b_{t}$, and $\tau$ and $g$ are parameters related to Treasury taxes and purchases as described below.

If Treasury taxes were $T_{t}^{T}=\tau A_{t} K_{t}$ and if government purchases were $G_{t}=g A_{t} K_{t}$, then $(g-\tau)\left(A_{t}-\bar{A}\right) K_{t}$ would be the amount by which net government expenditures (i.e., government purchases less taxes) in period $t$ exceed the amount that was expected at the end of the previous period (when $K_{t}$ was known). The Treasury can respond to unexpected net expenditures by increasing taxes, reducing government purchases, or increasing its outstanding debt. If the Treasury completely insulates the size of its debt from unexpected shocks by changing taxes and government purchases appropriately, then $\rho_{A}=0$ in equation (18). Alternatively, if $\rho_{A}>0$, then the Treasury finances at least part of unexpected net expenditures by increasing its debt.

Let $D_{t}$ be the primary deficit in period $t$. Since the primary deficit is the amount by which government purchases (which do not include interest payments on government debt) exceed taxes, the Treasury's budget constraint in equation (17) implies

$$
D_{t}=G_{t}-T_{t}^{T}=B_{t+1}-r_{t} B_{t}
$$

The Treasury policy function in equation (18) implies a value for the primary deficit. Multiplying both sides of equation (18) by $K_{t+1}$, substituting the resulting expression for $B_{t+1}$ in equation (19), and recalling that $B_{t}=b_{t} K_{t}$ yields

$$
D_{t}=\left[\beta+\rho_{B}\left(b_{t}-\beta\right)+\rho_{A}(g-\tau)\left(A_{t}-\bar{A}\right)\right] K_{t+1}-r_{t} b_{t} K_{t} .
$$

Given the value of the primary deficit in equation (20), the values of $G_{t}$ and $T_{t}^{T}$ still need to be determined. To the extent that $D_{t}$ in equation (20) differs from $(g-\tau) A_{t} K_{t}$, government purchases and/or taxes need to be adjusted. I introduce a "tax responsiveness" parameter $\lambda$ to determine how much of the required adjustment in $G_{t}-T_{t}^{T}$ is achieved by adjusting taxes. Whenever there is a gap between $D_{t}$ and $(g-\tau) A_{t} K_{t}$, a fraction $\lambda(0 \leq \lambda \leq 1)$ of this 
gap is closed by changing taxes, and a fraction $1-\lambda$ is closed by changing government purchases. Specifically,

$$
T_{t}^{T}=\tau A_{t} K_{t}-\lambda\left[D_{t}-(g-\tau) A_{t} K_{t}\right]
$$

and

$$
G_{t}=g A_{t} K_{t}+(1-\lambda)\left[D_{t}-(g-\tau) A_{t} K_{t}\right]
$$

The amount of taxes collected by the Treasury can be rewritten by substituting equation (20) into equation (21) to obtain ${ }^{11}$

$$
\begin{aligned}
T_{t}^{T}= & {[(1-\lambda) \tau+\lambda g] A_{t} K_{t}+\lambda r_{t} b_{t} K_{t} } \\
& -\lambda\left[\beta+\rho_{B}\left(b_{t}-\beta\right)+\rho_{A}(g-\tau)\left(A_{t}-\bar{A}\right)\right] K_{t+1} .
\end{aligned}
$$

The expression for Treasury tax revenue in equation (23) can be simplified in special cases. For instance, if the tax responsive parameter $\lambda$ equals zero, the Treasury's tax revenue is simply $T_{t}^{T}=\tau A_{t} K_{t} .{ }^{12} \quad$ In this case, any gap between the primary deficit and $(g-\tau) A_{t} K_{t}$ is closed completely by adjusting government purchases.

\section{The Social Security System}

The Social Security system collects taxes from young people and pays benefits to old people. Any excess of taxes over benefits is added to the Social Security Trust Fund, and any excess of benefits over taxes is paid from the Social Security Trust Fund.

Let $S_{t}$ be the value of the Social Security Trust Fund at the beginning of period $t$. Currently in the United States, the Social Security Trust Fund is invested entirely in Treasury bonds which pay a rate of return $r_{t}$. However, there are proposals to invest part of the Social Security Trust Fund in equities, which are modeled as risky capital in this paper. To account for this possible change, let $K_{t}^{S}$ be the amount of risky capital held by the Social Security

\footnotetext{
${ }^{11}$ Government purchases can be rewritten as $G_{t}=[\lambda g+(1-\lambda) \tau] A_{t} K_{t}-$ $(1-\lambda) r_{t} b_{t} K_{t}+(1-\lambda)\left[\beta+\rho_{B}\left(b_{t}-\beta\right)+\rho_{A}(g-\tau)\left(A_{t}-\bar{A}\right)\right] K_{t+1}$.

${ }^{12}$ One might think of this case as being one of complete tax smoothing by the Treasury, though it must be noted that since all taxes are lump-sum, the usual argument for tax smoothing does not apply here.
} 
Trust Fund at the beginning of period $t$, and define $\gamma_{S, t} \equiv \frac{K_{t}^{S}}{S_{t}} \geq 0$ as the fraction of the Social Security Trust Fund invested in risky capital with a rate of return $R_{t}$. The condition $\gamma_{S, t} \geq 0$ rules out the possibility that the Social Security Trust Fund takes a short position in risky physical capital.

Let $B_{t}^{S}$ be the value of riskless bonds held by the Social Security Trust Fund at the beginning of period $t$, and note that $1-\gamma_{S, t}=\frac{B_{t}^{S}}{S_{t}}$ is the fraction of the Social Security Trust Fund invested in riskless bonds. The rate of return on the Social Security Trust Fund, $R_{t}^{S}$, is

$$
R_{t}^{S} \equiv\left(1-\gamma_{S, t}\right) r_{t}+\gamma_{S, t} R_{t} .
$$

The budget constraint of the Social Security Trust Fund is

$$
S_{t+1}=R_{t}^{S} S_{t}+T_{t}^{S}-Q_{t} .
$$

I have described the behavior of Social Security benefits, $Q_{t}$, and the rate of return $R_{t}^{S}$. To complete the description of the behavior of the Social Security system I must either specify the behavior of Social Security taxes, $T_{t}^{S}$, or the evolution of the size of the trust fund $S_{t}$. I will specify the evolution of $S_{t}$, and thus $T_{t}^{S}$ will be determined as a residual from equation (25). ${ }^{13}$

Define $s_{t} \equiv \frac{S_{t}}{K_{t}}$ as the ratio of the Social Security Trust Fund to the aggregate capital stock, and let $\sigma$ be the "target" value of $s_{t}$. The Social Security system does not aim to set $s_{t}$ equal to $\sigma$ in every period, but it tries to prevent $s_{t}$ from wandering too far from $\sigma$ by adhering to the following policy function

$$
s_{t+1}-\sigma=\rho_{S}\left(s_{t}-\sigma\right)+\rho_{R}\left(R_{t}^{S}-\bar{R}_{t}^{S}\right) s_{t}
$$

\footnotetext{
${ }^{13}$ I have specified the Social Security system as a pay-as-you-go defined-benefit system, but the framework is flexible enough to model a fully-funded defined-contribution system in which the Social Security taxes collected from workers are placed in the Social Security Trust Fund. A fully-funded defined-contribution system can be modeled by specifying the amount taxes collected from workers, $T_{t}^{S}$, and the fraction of the Social Security Trust Fund invested in risky capital, $\gamma_{S, t+1}$. The size of the Social Security Trust Fund at the beginning of period $t+1$ is $S_{t+1}=T_{t}^{S}$, and the Social Security benefits in period $t+1$ are $Q_{t+1}=R_{t+1}^{S} S_{t+1}=\left(1-\gamma_{S, t+1}\right) r_{t+1} S_{t+1}+\gamma_{S, t+1} R_{t+1} S_{t+1}$. Comparing this expression for Social Security benefits to the expression in equation (8), and recalling that $S_{t+1}=s_{t+1} K_{t+1}$, implies the following values for $\theta_{0}$ and $\theta_{1}: \theta_{0}=\frac{\left(1-\gamma_{S, t+1}\right) r_{t+1} s_{t+1}}{(1-\alpha) \bar{A}}$ and $\theta_{1}=\frac{\alpha \gamma_{S, t+1} s_{t+1}}{1-\alpha}$. A fully-funded defined-contribution Social Security system has no effect on the equilibrium riskless interest rate (see footnote 14) or on the growth rate of capital (see footnote 19).
} 
where $\bar{R}_{t}^{S} \equiv\left(1-\gamma_{S, t}\right) r_{t}+\gamma_{S, t} \bar{R}$ is the expected value of $R_{t}^{S}$ conditional on information available at the end of period $t-1$, and $\rho_{S} \geq 0$ and $\rho_{R} \geq 0$ are constants that parametrize the evolution of the Social Security Trust Fund relative to the capital stock. If $\rho_{R}=0$, the size of the Social Security Trust Fund is completely insulated from shocks to the rate of return, $R_{t}^{S}$. In this case, the ratio of the Social Security Trust Fund to the capital stock, $s_{t+1}$, is always equal to the target value $\sigma$. If $\rho_{R}>0$, then when the return on the Social Security Trust Fund, $R_{t}^{S}$, is higher than expected, at least part of the unexpected return is used to increase the size of the Social Security Trust Fund. The parameter $\rho_{S}$ measures the persistence of changes in the ratio $s_{t}$.

The amount of Social Security taxes, $T_{t}^{S}$, is determined as a residual from equation (25). Substituting equation (26) into equation (25), using equation (24), and solving for $T_{t}^{S}$ yields

$$
T_{t}^{S}=Q_{t}-R_{t}^{S} s_{t} K_{t}+\left[\sigma+\rho_{S}\left(s_{t}-\sigma\right)+\rho_{R} \gamma_{S, t}\left(R_{t}-\bar{R}\right) s_{t}\right] K_{t+1} .
$$

\section{General Equilibrium}

Now that I have specified the behavior of firms, individuals, the Treasury, and the Social Security system, I will analyze the general equilibrium that arises when these economic actors interact in capital markets. The dynamic general equilibrium describes the equilibrium evolution of four endogenous variables: the riskless interest rate $r_{t}$, the aggregate capital stock $K_{t}$, the debt-capital ratio $b_{t}$, and the Social Security Trust Fund-capital ratio $s_{t}$. The dynamic behavior of these four variables is governed by a nonlinear difference equation system that is recursive. Given the values of $r_{t}, K_{t}, b_{t}$, $s_{t}$, and the exogenous variable $A_{t}$ (and the implied value of $R_{t}$ ), the value of $b_{t+1}$ is determined by the Treasury policy function in equation (18), and the value of $s_{t+1}$ is determined by the Social Security policy function in equation (26). As I will show below, the equilibrium value of $r_{t+1}$ is determined by the optimal portfolio shares using the values of $b_{t+1}$ and $s_{t+1}$. Finally, the value of $K_{t+1}$ is determined using optimal saving behavior and the values of $r_{t+1}, b_{t+1}$, and $s_{t+1}$.

I consider a closed economy so that all of the bonds issued by the Treasury, $B_{t+1}$, are held by either the domestic private sector, which holds the amount $B_{t+1}^{P}$, or by the Social Security Trust Fund, which holds the amount 
$\left(1-\gamma_{S, t+1}\right) S_{t+1}$. Therefore,

$$
B_{t+1}^{P}=B_{t+1}-\left(1-\gamma_{S, t+1}\right) S_{t+1} .
$$

Similarly, all of the capital in the economy, $K_{t+1}$, is held either by the domestic private sector, which holds the amount $K_{t+1}^{P}$, or by the Social Security Trust Fund, which holds $\gamma_{S, t+1} S_{t+1}$. Therefore,

$$
K_{t+1}^{P}=K_{t+1}-\gamma_{S, t+1} S_{t+1}
$$

I will restrict attention to equilibria in which the amount of Treasury debt outstanding, $B_{t}$, is positive, the Social Security Trust Fund, $S_{t}$, is nonnegative, and young consumers hold positive amounts of both bonds and capital in their portfolios. Since $\gamma_{S, t+1} \geq 0$, equation (28) implies that a sufficient condition for young consumers to have positive holdings of bonds is

$$
b_{t+1}>s_{t+1} .
$$

Equation (29) implies that young consumers will have positive holdings of risky capital in equilibrium if

$$
\gamma_{S, t+1} s_{t+1}<1
$$

Henceforth, I will assume that the conditions in equations (30) and (31) hold for all $t$.

\subsection{The Equilibrium Riskless Interest Rate}

The equilibrium riskless interest rate is determined by the optimal portfolio shares. It follows from equations (15) and (16) that

$\gamma\left(r_{t+1}\right)\left(B_{t+1}^{P}+\frac{\theta_{0}(1-\alpha) \bar{A} K_{t+1}}{r_{t+1}}\right)=\left[1-\gamma\left(r_{t+1}\right)\right]\left(K_{t+1}^{P}+\theta_{1} \frac{1-\alpha}{\alpha} K_{t+1}\right)$.

Using equations (28) and (29), and the definitions $b_{t+1} \equiv \frac{B_{t+1}}{K_{t+1}}$ and $s_{t+1} \equiv$ $\frac{S_{t+1}}{K_{t+1}}$, equation $(32)$ can be rewritten as

$$
\begin{aligned}
0= & \gamma\left(r_{t+1}\right)\left(1+b_{t+1}-s_{t+1}+\frac{\theta_{0}(1-\alpha) \bar{A}}{r_{t+1}}+\theta_{1} \frac{1-\alpha}{\alpha}\right) \\
& -1+\gamma_{S, t+1} s_{t+1}-\theta_{1} \frac{1-\alpha}{\alpha}
\end{aligned}
$$


Equation (33) determines the equilibrium riskless interest rate $r_{t+1} \cdot{ }^{14} \mathrm{Al}-$ ternatively, it can be solved to obtain the equilibrium value of $\gamma\left(r_{t+1}\right)$ which is

$$
\gamma\left(r_{t+1}\right)=\frac{1+\theta_{1} \frac{1-\alpha}{\alpha}-\gamma_{S, t+1} s_{t+1}}{1+\theta_{1} \frac{1-\alpha}{\alpha}+b_{t+1}-s_{t+1}+\frac{\theta_{0}(1-\alpha) \bar{A}}{r_{t+1}}} .
$$

Equation (34) along with the conditions in equations (30) and (31) imply

Proposition 1 In equilibrium, $0<\gamma\left(r_{t+1}\right)<1$.

This proposition states that in equilibrium young consumers hold positive amounts of risky assets in their portfolios. It is well-known that an optimal portfolio will include positive holdings of risky assets only if the expected rate of return on risky assets is greater than the riskless rate of return. ${ }^{15}$ Thus, Proposition 1 implies the following corollary.

Corollary 1 In equilibrium, $r_{t+1}<\bar{R}$.

The following proposition, which is proved in Appendix $\mathrm{C}$, describes the properties of the equilibrium riskless rate of return defined implicitly in equation (33).

Proposition 2 Suppose that $\gamma^{\prime}\left(r_{t+1}\right)<0 .{ }^{16}$ Let $r\left(b_{t+1}, s_{t+1}, \gamma_{S, t+1}, \theta_{0}, \theta_{1}\right)$ be the unique value of $r_{t+1}$ that satisfies equation (33). Then

\footnotetext{
${ }^{14}$ In a fully-funded defined-contribution system, $\frac{\theta_{0}(1-\alpha) \bar{A}}{r_{t+1}}+\theta_{1} \frac{1-\alpha}{\alpha}=s_{t+1}$, and $\theta_{1} \frac{1-\alpha}{\alpha}=\gamma_{S, t+1} s_{t+1}$, as may be verified using the expressions for $\theta_{0}$ and $\theta_{1}$ in footnote 13. In this case, the equilibrium condition for the riskless interest rate in equation (33) becomes $0=\gamma\left(r_{t+1}\right)\left(1+b_{t+1}\right)-1$, which implies that the equilibrium riskless interest rate is independent of changes in the size or portfolio allocation of a fully-funded definedcontribution Social Security system.

${ }^{15}$ For any strictly increasing, strictly concave function $u(), u^{\prime}(r+\gamma(R-r))(R-r)<$ $u^{\prime}(r)(R-r)$ if $R-r \neq 0$ and $\gamma>0$. Thus, for nondegenerate distributions of $R, E\left\{u^{\prime}(r+\gamma(R-r))(R-r)\right\}<u^{\prime}(r) E\{R-r\}$. Therefore, if $E\{R\} \leq r$, $E\left\{u^{\prime}(r+\gamma(R-r))(R-r)\right\}<0$, and the condition for the optimal value of $\gamma$, $E\left\{u^{\prime}(r+\gamma(R-r))(R-r)\right\}=0$, cannot hold. Thus, in order for the optimal value of $\gamma$ to be positive, $E\{R\}$ must exceed $r$.

${ }^{16}$ As shown in Appendix B, the condition $\gamma^{\prime}\left(r_{t+1}\right)<0$ holds if $\phi \leq 1$. If $\phi>1$, then $\gamma^{\prime}\left(r_{t+1}\right)$ may not be negative for some values of $r_{t+1}$, so the proof of uniqueness does not hold. Nevertheless, the effects on $r_{t+1}$ of changes in $b_{t+1}, s_{t+1}, \gamma_{S, t+1}, \theta_{0}$, and $\theta_{1}$ in this proposition hold for any solution to equation (33) for which $\gamma^{\prime}\left(r_{t+1}\right)<0$. As mentioned in footnote 8 , this condition holds for all cases in Tables 1,2 , and 3 .
} 


$$
\begin{aligned}
& \frac{\partial r}{\partial b_{t+1}}>0, \\
& \operatorname{sign}\left(\frac{\partial r}{\partial s_{t+1}}\right)=\operatorname{sign}\left(\gamma_{S, t+1}-\gamma\left(r_{t+1}\right)\right), \\
& \operatorname{sign}\left(\frac{\partial r}{\partial \gamma_{S, t+1}}\right)=\operatorname{sign}\left(s_{t+1}\right) \\
& \frac{\partial r}{\partial \theta_{0}}>0 \\
& \frac{\partial r}{\partial \theta_{1}}<0
\end{aligned}
$$

Before interpreting the various effects in Proposition 2, it is worth recalling that since the risky rate of return $R_{t+1}$ is invariant to policy in this model, any change in the riskless interest rate is equivalent to a change in the equity premium of the same magnitude but in the opposite direction.

An increase in $b_{t+1}$, the ratio of Treasury bonds to the capital stock, increases the equilibrium interest rate in order to induce private investors to devote a larger share of their portfolios to riskless bonds. Similarly, if the Social Security Trust Fund has a positive balance $\left(s_{t+1}>0\right)$ and sells some riskless bonds in exchange for stock, thereby increasing $\gamma_{S, t+1}$, the equilibrium interest rate on bonds must increase in order for private investors to be willing to hold a higher ratio of bonds to stocks directly in their own portfolios. ${ }^{17}$

The effect of an increase in the size of the Social Security Trust Fund, represented as an increase in $s_{t+1}$, depends on the sign of $\gamma_{S, t+1}-\gamma\left(r_{t+1}\right)$. If the share of the Social Security Trust held in risky capital $\left(\gamma_{S, t+1}\right)$ is smaller than the share of private portfolios held in risky capital, as is the case in the United States where $\gamma_{S, t+1}=0$, then an increase in the size of the Social Security Trust Fund, $s_{t+1}$, effectively reduces the ratio of riskless bonds to risky capital available to private investors. In order for these investors to willingly reduce the ratio of riskless bonds to risky capital in their portfolios, the riskless interest rate must fall.

The "replacement rates" $\theta_{0}$ and $\theta_{1}$ have opposite effects on the equilibrium riskless interest rate. An increase in $\theta_{0}$ increases the riskless component of the Social Security benefit that young people anticipate and effectively increases the holding of riskless assets by young people. In order for these people to be willing to increase their riskless holdings, the riskless interest rate must increase. However, an increase in $\theta_{1}$ increases the risky component of the Social Security benefit that young consumers anticipate and effectively

\footnotetext{
${ }^{17}$ Recall that the Social Security system analyzed here is a defined-benefit system, so the change in the portfolio allocation of the Social Security Trust Fund does not affect the claims on future Social Security benefits held by workers.
} 
increases the holding of risky assets in private portfolios. The riskless interest rate must fall in order to induce consumers to be willing to hold an increased share of risky assets in their portfolios.

The equilibrium condition in equation (33) illustrates the extent to which the separate balance sheets of the Treasury and the Social Security Trust Fund can be consolidated for the purpose of determining the equilibrium riskless interest rate. Inspection of equation (33) implies the following proposition.

Proposition 3 For the purpose of determining the equilibrium riskless interest rate, all of the information on the balance sheets of the Treasury and the Social Security Trust Fund is captured by $\nu_{t+1} \equiv b_{t+1}-s_{t+1}+\frac{\gamma_{S, t+1}}{\gamma\left(r_{t+1}\right)} s_{t+1}$.

Corollary 2 If $\gamma_{S, t+1}=0$, then the effects of $b_{t+1}$ and $s_{t+1}$ on the riskless interest rate are captured entirely by $b_{t+1}-s_{t+1}$.

If $\gamma_{S, t+1}=0$, as is currently the case in the United States, the Social Security Trust Fund is held entirely in riskless bonds. In this case, for the purpose of determining the equilibrium riskless interest rate, the balance sheets of the Treasury and the Social Security Trust Fund can be consolidated. The only information needed from the separate balance sheets of these entities is the net amount of bonds, normalized by the aggregate capital stock, $b_{t+1}-s_{t+1}$, issued by the consolidated entity. However, even in this case, the balance sheets of the Treasury and the Social Security Trust Fund cannot, in general, be consolidated for the purpose of determining the growth rate of the capital stock. (See Proposition 4 in subsection 5.2 for the more stringent conditions under which these balance sheets can be consolidated for the purpose of determining the growth rate of the capital stock.)

Corollary 3 If $\gamma_{S, t+1}=\gamma\left(r_{t+1}\right)$, then the effects of $b_{t+1}$ and $s_{t+1}$ on the riskless interest rate are captured entirely by $b_{t+1}$.

According to this corollary, if the Social Security Trust Fund maintains a risky portfolio share $\gamma_{S, t+1}$ equal to the share of risky assets in private portfolios, ${ }^{18} \gamma\left(r_{t+1}\right)$, the equilibrium interest rate is independent of the size

\footnotetext{
${ }^{18}$ Recall that $\gamma\left(r_{t+1}\right)$ is the share of risky assets, which include risky capital and the claim on risky future Social Security benefits, in the portfolios of young consumers, which consist of bonds, risky capital, and the riskless and risky components of future Social Security benefits.
} 
of the Social Security Trust Fund. In this case, changes in the size of the Social Security Trust Fund have no effect on the ratio of riskless assets to risky assets available to the private sector, and hence the equilibrium riskless interest rate is unaffected by such changes.

\subsection{The Growth Rate of the Capital Stock}

In this subsection I use the optimal saving behavior of individuals, along with the saving behavior of the Treasury and the Social Security system, to determine how much capital is accumulated in the economy. Then I will analyze how the growth rate of the aggregate capital stock is affected by a change in the portfolio of the Social Security Trust Fund.

In a closed economy, the bonds and capital held by the private sector, $B_{t+1}^{P}+K_{t+1}^{P}$, plus the value of the Social Security Trust Fund, $S_{t+1}$, equal the aggregate capital stock, $K_{t+1}$, plus the value of bonds issued by the Treasury, $B_{t+1}$. This relationship can be derived by adding equations (28) and (29) to obtain

$$
B_{t+1}+K_{t+1}=B_{t+1}^{P}+K_{t+1}^{P}+S_{t+1} .
$$

The size of the portfolio of the private sector, $B_{t+1}^{P}+K_{t+1}^{P}$, can be calculated from equations (11), (15), and (16) to obtain

$$
\begin{aligned}
B_{t+1}^{P}+K_{t+1}^{P}= & \frac{\delta}{1+\delta}\left(w_{t}-T_{t}^{T}-T_{t}^{S}\right) \\
& -\frac{1}{1+\delta}\left(\frac{\theta_{0}(1-\alpha) \bar{A}}{r_{t+1}}+\theta_{1} \frac{1-\alpha}{\alpha}\right) K_{t+1} .
\end{aligned}
$$

The growth rate of the capital stock can be determined by substituting equation (36) into (35) and performing a tedious set of substitutions. To streamline the notation, define

$$
\omega_{t} \equiv\left(s_{t}, b_{t}, A_{t}, \theta_{0}, \theta_{1}\right) .
$$

Appendix D shows that ${ }^{19}$

$$
\frac{K_{t+1}}{K_{t}}=\frac{H_{0}\left(r_{t}, \gamma_{S, t}, \omega_{t}\right)}{H_{1}\left(r_{t+1}, \gamma_{S, t}, \omega_{t}\right)}
$$

\footnotetext{
${ }^{19}$ In a fully-funded defined-contribution Social Security system, $-(1-\alpha)\left(\theta_{0} \bar{A}+\theta_{1} A_{t}\right)+\left[\left(1-\gamma_{S, t}\right) r_{t}+\gamma_{S, t} R_{t}\right] s_{t}=\left(-\alpha A_{t}+R_{t}\right) \gamma_{S, t} s_{t}=0$,
} 
where

$$
H_{0}\left(r_{t}, \gamma_{S, t}, \omega_{t}\right) \equiv \delta\left(\begin{array}{c}
{[1-\alpha-(1-\lambda) \tau-\lambda g] A_{t}} \\
-(1-\alpha)\left(\theta_{0} \bar{A}+\theta_{1} A_{t}\right) \\
+\left[\left(1-\gamma_{S, t}\right) r_{t}+\gamma_{S, t} R_{t}\right] s_{t}-\lambda r_{t} b_{t}
\end{array}\right)
$$

and

$$
\begin{aligned}
H_{1}\left(r_{t+1}, \gamma_{S, t}, \omega_{t}\right) \equiv & 1+\delta+\frac{\theta_{0}(1-\alpha) \bar{A}}{r_{t+1}}+\theta_{1} \frac{1-\alpha}{\alpha} \\
& +(1+\delta-\delta \lambda)\left[\beta+\rho_{B}\left(b_{t}-\beta\right)+\rho_{A}(g-\tau)\left(A_{t}-\bar{A}\right)\right] \\
& -\left[\sigma+\rho_{S}\left(s_{t}-\sigma\right)+\rho_{R}\left(R_{t}-\bar{R}\right) \gamma_{S, t} s_{t}\right]
\end{aligned}
$$

I will restrict attention to cases in which $H_{0}>0$ and $H_{1}>0$. Though $H_{0}$ and $H_{1}$ defy simple interpretations that are literally correct, for the sake of exposition I will offer loose interpretations. The term $H_{0}$ can be loosely interpreted as the disposable income of the young consumers, ${ }^{20}$ and factors that increase the disposable income of the young consumers tend to increase capital accumulation. The term $H_{1}$ can be loosely interpreted as the ratio of non-capital wealth held by young consumers to the aggregate capital stock, where the non-capital wealth consists of Treasury bonds and claims on Social Security benefits. ${ }^{21}$ Factors that increase this ratio tend to reduce capital accumulation.

Inspection of equations (39) and (40) implies the following proposition about the consolidation of the balance sheets of the Treasury and the Social Security Trust Fund.

where the first equality follows from the expressions for $\theta_{0}$ and $\theta_{1}$ in footnote 13 , and the second equality follows from equation (5). Therefore, $H_{0}\left(r_{t}, \gamma_{S, t}, \omega_{t}\right)=$ $\delta\left([1-\alpha-(1-\lambda) \tau-\lambda g] A_{t}-\lambda r_{t} b_{t}\right)$. Using the fact that $\frac{\theta_{0}(1-\alpha) \bar{A}}{r_{t+1}}+\theta_{1} \frac{1-\alpha}{\alpha}=s_{t+1}$ (see footnote 13) along with the Social Security policy function in equation (26), $H_{1}\left(r_{t+1}, \gamma_{S, t}, \omega_{t}\right)=1+\delta+(1+\delta-\delta \lambda)\left[\beta+\rho_{B}\left(b_{t}-\beta\right)+\rho_{A}(g-\tau)\left(A_{t}-\bar{A}\right)\right]$. Since both $H_{0}$ and $H_{1}$ are independent of parameters of a fully-funded defined-contribution Social Security system, the growth rate of the capital stock, $K_{t+1} / K_{t}=H_{0} / H_{1}$, is independent of parameters of a such a system.

${ }^{20}$ More precisely, if $s_{t}=\sigma, A_{t}=\bar{A}$, and $b_{t}=\beta$, then $H_{0} K_{t}=$ $\delta\left(w_{t}-T_{t}^{T}-T_{t}^{S}-\lambda \beta K_{t+1}+\sigma K_{t+1}\right)$. If $\beta=\sigma=0$, then $H_{0} K_{t}$ is strictly proportional to the disposable income of young consumers, $w_{t}-T_{t}^{T}-T_{t}^{S}$.

${ }^{21}$ More precisely, if $\lambda=1, H_{1}=1+\delta+\frac{\theta_{0}(1-\alpha) \bar{A}}{r_{t+1}}+\theta_{1} \frac{1-\alpha}{\alpha}+b_{t+1}-s_{t+1}$, where $\frac{\theta_{0}(1-\alpha) \bar{A}}{r_{t+1}}+$ $\theta_{1} \frac{1-\alpha}{\alpha}$ is the present value of the claim on future Social Security benefits relative to the aggregate capital stock $K_{t+1}$, and if $\gamma_{S, t+1}=0, b_{t+1}-s_{t+1}$ is the amount of Treasury bonds held by young consumers relative to the aggregate capital stock. 
Proposition 4 If $\gamma_{S, t}=0, \lambda=1$, and $\rho_{S}=\rho_{B}$, then for the purpose of determining the growth rate of the capital stock, all of the information on the balance sheets of the Treasury and the Social Security Trust Fund is captured by $b_{t}-s_{t}$, and the information contained in the targets $\beta$ and $\sigma$ is captured by $\beta-\sigma$.

Recall from Corollary 2 that if the Social Security Trust Fund holds only riskless bonds, then for the purpose of determining the riskless interest rate, the balance sheets of the Treasury and the Social Security Trust Fund can be consolidated. For the purpose of determining the $r_{t}$, the net indebtedness of the consolidated entity, $b_{t}-s_{t}$, is a sufficient statistic for $b_{t}$ and $s_{t}$. However, for the purpose of determining the growth rate of the capital stock, a more stringent set of conditions is required to be able to consolidate the balance sheets of the Treasury and the Social Security Trust Fund. In addition to $\gamma_{S, t}=0$, the parameter $\lambda$ must equal one, and the persistence parameters $\rho_{B}$ and $\rho_{S}$ must be equal. The parameter $\lambda$ must equal one because all adjustment in the net income of the Social Security system takes place through adjusting the taxes on the young. With $\lambda=1$, all adjustment in the net income of the Treasury will also take place through adjusting taxes on the young.

The following two Lemmas help prove and interpret the effects of changes in the portfolio of the Social Security system on the growth rate of the capital stock.

Lemma $1 \frac{\partial H_{0}\left(r_{t}, \gamma_{S}, \omega_{t}\right)}{\partial r_{t}}=\delta\left[\left(1-\gamma_{S, t}\right) s_{t}-\lambda b_{t}\right]$.

Consider an increase in $r_{t}$ that increases the amount of interest paid by the Treasury during period $t$ by $b_{t}$ dollars. This increase in $r_{t}$ will increase the amount of interest received by the Social Security Trust Fund by $\left(1-\gamma_{S, t}\right) s_{t}$ dollars. ${ }^{22}$ According to the Social Security policy function in equation (26), the Social Security system will not change the size of the trust fund in period $t+1$ and thus will use the additional interest earnings to reduce Social Security taxes in period $t$ by $\left(1-\gamma_{S, t}\right) s_{t}$ dollars. According to the Treasury policy function in equation (18), the Treasury will not change the size of its debt and thus will respond to the increased cost of debt service by

\footnotetext{
${ }^{22}$ The increase in interest payments by the Treasury is $B_{t} \Delta r_{t}=b_{t}$, which implies that $\Delta r_{t}=\frac{b_{t}}{B_{t}}=\frac{1}{K_{t}}$. The increase in the interest earned by the Social Security Trust Fund is $\left(1-\gamma_{S, t}\right) S_{t} \Delta r_{t}=\left(1-\gamma_{S, t}\right) S_{t} \frac{1}{K_{t}}=\left(1-\gamma_{S, t}\right) s_{t}$.
} 
increasing taxes by $\lambda b_{t}$ dollars. Taking account of both Social Security taxes and Treasury taxes, the total taxes paid by young consumers in period $t$ fall by $\left(1-\gamma_{S, t}\right) s_{t}-\lambda b_{t}$ dollars, and the disposable income of young consumers increases by this amount. If $\left(1-\gamma_{S, t}\right) s_{t}-\lambda b_{t}>0$, the increase in disposable income of young consumers increases $H_{0}$ and increases the size of portfolios held by young consumers.

A change in the riskless interest rate $r_{t+1}$ affects $H_{1}$ as described in the following lemma.

Lemma $2 \frac{\partial H_{1}\left(r_{t+1}, \gamma_{S, t}, \omega_{t}\right)}{\partial r_{t+1}}=-\frac{\theta_{0}(1-\alpha) \bar{A}}{r_{t+1}^{2}} \leq 0$.

If $\theta_{0}>0$, an increase in $r_{t+1}$ reduces present value of the claim on future riskless Social Security benefits held by young consumers, thereby reducing $H_{1}$, the ratio of non-capital wealth to capital in the portfolios of young consumers.

Now consider a change in $\gamma_{S, t+1}$, the share of the Social Security Trust Fund that is held in risky capital. The following proposition applies to a change in the portfolio of the Social Security Trust Fund at the end of period $t$ after $b_{t}, s_{t}, r_{t}$, and $K_{t}$ have been determined.

Proposition 5 If $\theta_{0}>0$ and $s_{t+1}>0$, then $\left.\frac{d K_{t+1}}{d \gamma_{S, t+1}}\right|_{K_{t}, r_{t}, \omega_{t}}>0$.

Proof. $\left.\frac{d K_{t+1}}{d \gamma_{S, t+1}}\right|_{K_{t}, r_{t}, \omega_{t}}=-\frac{H_{0}}{H_{1}^{2}} \frac{\partial H_{1}}{\partial r_{t+1}} \frac{\partial r_{t+1}}{\partial \gamma_{S, t+1}}>0$ because $\frac{\partial H_{1}}{\partial r_{t+1}}=-\frac{\theta_{0}(1-\alpha) \bar{A}}{r_{t+1}^{2}}<$ 0 (from Lemma 2) and sign $\left(\frac{\partial r_{t+1}}{\partial \gamma_{S, t+1}}\right)=\operatorname{sign}\left(s_{t+1}\right)$ (from Proposition 2).

An increase in $\gamma_{S, t+1}$ has no direct effect on either $H_{0}\left(r_{t}, \gamma_{S, t}, \omega_{t}\right)$ or $H_{1}\left(r_{t+1}, \gamma_{S, t}, \omega_{t}\right)$. However, an increase in $\gamma_{S, t+1}$ increases the riskless interest rate $r_{t+1}$, provided that $s_{t+1}>0$. The resulting increase in $r_{t+1}$ reduces the present value of riskless Social Security benefits which implies that the present value of lifetime resources, $\Omega_{t}$, falls. In response to the fall in $\Omega_{t}$, consumers reduce their consumption and increase their saving so that national capital accumulation increases.

Corollary 4 If $\theta_{0}=0$ or $s_{t+1}=0$, then $\left.\frac{d K_{t+1}}{d \gamma_{S, t+1}}\right|_{K_{t}, r_{t}, \omega_{t}}=0$.

This corollary implies, for instance, that if all Social Security benefits are risky, so that $\theta_{0}=0$, then a change in the portfolio of the Social Security Trust Fund at the end of period $t$ will have no effect on $K_{t+1}$. 


\subsubsection{Constant Growth Paths}

I have shown that given the capital stock $K_{t}$ and the riskless interest rate $r_{t}$, an increase in the risky share of the Social Security Trust Fund, $\gamma_{S, t+1}$, at the end of period $t$ increases the riskless interest rate $r_{t+1}$ and the aggregate capital stock $K_{t+1}$ in the following period. In this section, I focus on the long-run effects of a change in the portfolio allocation of the Social Security Trust Fund. I will focus on constant growth paths, which I define to be paths along which $\gamma_{S, t}=\gamma_{S}$ and $A_{t}=\bar{A}$ for all $t$, so that $R_{t}=\bar{R}, b_{t}=\beta$, and $s_{t}=\sigma$ for all $t .^{23}$ Along such paths, the riskless interest rate and the growth rate of capital will be constant. Let $r$ denote the constant value of the riskless interest rate along a constant growth path, and let $\eta$ be the constant value of $\frac{K_{t+1}}{K_{t}}$ along a constant growth path.

The equilibrium condition for the interest rate along a constant growth path is derived by substituting $b_{t+1}=\beta$ and $s_{t+1}=\sigma$ into equation (33) to obtain

$$
\gamma(r)\left(1+\beta-\sigma+\frac{\theta_{0}(1-\alpha) \bar{A}}{r}+\theta_{1} \frac{1-\alpha}{\alpha}\right)-1+\gamma_{S} \sigma-\theta_{1} \frac{1-\alpha}{\alpha}=0 .
$$

Similarly, the values of $H_{0}$ and $H_{1}$ along a constant growth path are derived by setting $\gamma_{S, t}=\gamma_{S}, A_{t}=\bar{A}, R_{t}=\bar{R}, b_{t}=\beta$ and $s_{t}=\sigma$ in equations (39) and (40) to obtain

$$
H_{0}^{*}\left(r, \gamma_{S}, \sigma, \beta, \bar{A}, \theta_{0}, \theta_{1}\right) \equiv \delta\left(\begin{array}{c}
{\left[(1-\alpha)\left(1-\theta_{0}-\theta_{1}\right)-(1-\lambda) \tau-\lambda g\right] \bar{A}} \\
+\left[\left(1-\gamma_{S}\right) r+\gamma_{S} \bar{R}\right] \sigma-\lambda r \beta
\end{array}\right)
$$

and

$$
\begin{aligned}
H_{1}^{*}\left(r, \gamma_{S}, \sigma, \beta, \bar{A}, \theta_{0}, \theta_{1}\right) \equiv & 1+\delta+\frac{\theta_{0}(1-\alpha) \bar{A}}{r}+\theta_{1} \frac{1-\alpha}{\alpha} \\
& +(1+\delta-\delta \lambda) \beta-\sigma
\end{aligned}
$$

\footnotetext{
${ }^{23}$ Of course, consumers do not know in advance that the realizations of $A_{t}$ and $R_{t}$ will always be equal to their respective expectations, so they take account of risk in making portfolio allocation decisions.
} 
where the asterisks on $H_{0}^{*}$ and $H_{1}^{*}$ indicate that these terms are evaluated along a constant growth path.

The equilibrium condition in equation (41) for the riskless interest rate $r$ along a constant growth path is identical (with appropriate re-labelling of variables) to the equilibrium condition for the riskless interest rate in equation (33). Thus, the following corollary to Proposition 2 describes the response of the riskless interest rate to various changes along a constant growth.

Corollary 5 Suppose that $\gamma^{\prime}(r)<0$. Let $\widetilde{r}\left(\beta, \sigma, \gamma_{S}, \theta_{0}, \theta_{1}\right)$ be the unique value of $r$ that satisfies equation (41). Then

$\frac{\partial \widetilde{r}}{\partial \beta}>0$,

$\operatorname{sign}\left(\frac{\partial \widetilde{r}}{\partial \sigma}\right)=\operatorname{sign}\left(\gamma_{S}-\gamma(\widetilde{r})\right)$,

$\operatorname{sign}\left(\frac{\partial \widetilde{r}}{\partial \gamma_{S}}\right)=\operatorname{sign}(\sigma)$,

$\frac{\partial \widetilde{r}}{\partial \theta_{0}}>0$,

$\frac{\partial \tilde{r}}{\partial \theta_{1}}<0$.

Again recall that any change in the riskless interest rate is matched by a change in the equity premium of equal size but in the opposite direction.

Now consider the effect on $\eta$, the growth rate of the capital stock along a constant growth path, of a permanent change in $\gamma_{S}$.

Proposition 6 If $\delta\left[\left(1-\gamma_{S}\right) \sigma-\lambda \beta\right]+\eta \frac{\theta_{0}(1-\alpha) \bar{A}}{r^{2}} \geq 0$ along a constant growth path with $\sigma>0$, then $\frac{d \eta}{d \gamma_{S}}>0$.

Proof. $\frac{d \eta}{d \gamma_{S}}=\frac{1}{H_{1}^{*}}\left(\frac{\partial H_{0}^{*}}{\partial \gamma_{S}}+\frac{\partial H_{0}^{*}}{\partial r} \frac{\partial r}{\partial \gamma_{S}}\right)-\frac{\eta}{H_{1}^{*}}\left(\frac{\partial H_{1}^{*}}{\partial \gamma_{S}}+\frac{\partial H_{1}^{*}}{\partial r} \frac{\partial r}{\partial \gamma_{S}}\right)$

$=\frac{1}{H_{1}^{*}} \delta\left((\bar{R}-r) \sigma+\left[\left(1-\gamma_{S}\right) \sigma-\lambda \beta\right] \frac{\partial r}{\partial \gamma_{S}}\right)+\frac{\eta}{H_{1}^{*}}\left(\frac{\theta_{0}(1-\alpha) \bar{A}}{r^{2}} \frac{\partial r}{\partial \gamma_{S}}\right)$

$=\frac{\delta}{H_{1}^{*}}(\bar{R}-r) \sigma+\frac{1}{H_{1}^{*}}\left(\delta\left[\left(1-\gamma_{S}\right) \sigma-\lambda \beta\right]+\eta \frac{\theta_{0}(1-\alpha) \bar{A}}{r^{2}}\right) \frac{\partial r}{\partial \gamma_{S}}>0$, since $\bar{R}>$ $r$ (Corollary 1) and $\frac{\partial r}{\partial \gamma_{S}}>0$ (Corollary 5 ).

A permanent increase in $\gamma_{S}$ has a direct effect on $H_{0}^{*}$ and indirect effects on both $H_{0}^{*}$ and $H_{1}^{*}$ operating through the riskless interest rate. The direct effect on $H_{0}^{*}$ arises because an increase in $\gamma_{S}$ increases the average earnings of the Social Security Trust Fund as it shifts its portfolio toward assets with a higher expected rate of return. The increase in the average portfolio earnings of the Social Security Trust Fund allows the Social Security tax on young 
consumers to be reduced, thereby increasing their disposable income. The increase in the disposable income of young consumers increases the amount of capital they hold in their portfolios.

The indirect effects on $H_{0}^{*}$ and $H_{1}^{*}$ arise because an increase in $\gamma_{S}$ increases the riskless interest rate (Corollary 5). An increase in the riskless interest rate increases the interest earnings of the Social Security Trust Fund and increases the interest payments made by the Treasury. These changes in interest flows induce the Social Security system and the Treasury to change the amount of taxes collected from young consumers. As explained in the interpretation of Lemma 1, these changes in taxes increase the disposable income of young consumers by an amount proportional to $\left(1-\gamma_{S}\right) \sigma-\lambda \beta$, which is captured by the change in $H_{0}^{*}$. In addition, the increase in the riskless interest rate reduces $H_{1}^{*}$ by reducing the present value of the future riskless Social Security benefits to be received by young consumers. This reduction in $H_{1}^{*}$ increases the growth rate of the capital stock.

The direct effect on $H_{0}^{*}$ and the indirect effect on $H_{1}^{*}$ both increase the growth rate of the capital stock. However, the indirect effect on $H_{0}^{*}$ can increase or decrease the growth rate of the capital stock depending on whether $\left(1-\gamma_{S}\right) \sigma-\lambda \beta$ is positive or negative. Proposition 6 states a sufficient condition for the indirect effect on $H_{1}^{*}$ to dominate the indirect effect on $H_{0}^{*}$ so that an increase in $\gamma_{S}$ unambiguously increases $\eta$. Corollary 6 below presents a condition for the indirect effect on $H_{0}^{*}$ to increase $\eta$, so that there is no conflict between the indirect effect on $H_{0}^{*}$ and the indirect effect on $H_{1}^{*}$. In this case, of course, an increase in $\gamma_{S}$ increases $\eta$. Corollary 7 presents an even stronger condition that guarantees that an increase in $\gamma_{S}$ increases $\eta$. This condition, $\lambda=0$, can be interpreted as complete tax smoothing. Thus, in the presence of complete tax smoothing, an increase in $\gamma_{S}$ unambiguously increases the growth rate of the capital stock $\eta$.

Corollary 6 If $\left(1-\gamma_{S}\right) \sigma-\lambda \beta \geq 0$ along a constant growth path with $\sigma>0$, then $\frac{d \eta}{d \gamma_{S}}>0$.

Corollary 7 If $\lambda=0$ along a constant growth path with $\sigma>0$, then $\frac{d \eta}{d \gamma_{S}}>$ 0 . 


\section{Calibration of the Model}

In this section I calibrate the model for a constant growth path. This calibration will serve two purposes. First, the calibration will shed light on the quantitative plausibility of the model. Second, the calibration will provide a quantitative measure of the effect of a change in $\gamma_{S}$ on the growth rate of the capital stock. In particular, the calibration can be used to determine if the condition in Proposition 6 is satisfied so that an increase in $\gamma_{S}$ increases the capital stock growth rate $\eta$ along a constant growth path.

One approach to calibrating the model would be to specify values for the parameters of preferences and technology, the parameters of the Social Security policy function, the parameters of the Treasury policy function, and the distribution of the stochastic productivity variable $A_{t}$, and then to compute the implied values of the riskless interest rate $r$ and the growth rate of the capital stock $\eta$. I will make two modifications to this approach. The first modification, which is a trivial change, is to specify the distribution of the risky rate of return $R_{t}=\alpha A_{t}$ instead of specifying the distribution of $A_{t}$. The second modification is more fundamental. Instead of specifying the values of the preference parameters $\phi$ and $\delta$, and then computing the implied values of $r$ and $\eta$, I will find the values of the preference parameters $\phi$ and $\delta$ for which the values of $r$ and $\eta$ implied by the model match the corresponding empirical values, which I denote as of $\widehat{r}$ and $\widehat{\eta}$, respectively.

Because the coefficient of relative risk aversion $\phi$ affects only the portfolio allocation decision, while the time preference discount factor $\delta$ affects only the saving/consumption decision, the values of these parameters that match $\widehat{r}$ and $\widehat{\eta}$ can be determined separately. Specifically, the coefficient of relative risk aversion $\phi$ is determined by the riskless interest rate equilibrium condition in equation (41) with $\widehat{r}$ substituted for $r$. The empirical value $\widehat{r}$, along with the values of the other parameters in this equation, implies a value for $\gamma(\widehat{r})$. There is a unique value of the coefficient of relative risk aversion $\phi$ for which the optimal value of the portfolio share $\gamma$ equals the value of $\gamma(\widehat{r})$ implied by the equilibrium condition in equation $(41){ }^{24}$

The value of the time preference discount factor $\delta$ is chosen so that the growth rate of capital implied by the model, $\frac{H_{0}^{*}}{H_{1}^{*}}$, equals the empirical value

\footnotetext{
${ }^{24} \lim _{\phi \rightarrow \infty} \gamma^{*}=0$ and $\lim _{\phi \rightarrow 0} \gamma^{*}=\infty$, so there is at least one value of $\phi$ for which the optimal value $\gamma^{*}$ equals the value implied by the equilibrium condition for the riskless interest rate. As shown in equation (B.11) in Appendix B, $\frac{d \gamma^{*}}{d \phi}<0$ so that such a value of $\phi$ is unique.
} 
of the growth rate, $\widehat{\eta}$. Matching the implied and empirical values of the growth rate of capital yields

$$
H_{0}^{*}=\widehat{\eta} H_{1}^{*}
$$

Since $H_{0}^{*}$ and $H_{1}^{*}$ are both linear functions of the time preference discount factor $\delta$, equation (44) is a linear function of $\delta$ which can be easily solved for the value of $\delta$ that allows the model to match the empirical growth rate of capital.

Because individuals are assumed to live for only two periods, each period in the model is one half of an adult lifetime. The length of a period is important for variables, such as rates of return, and parameters, such as the rate of time preference, that are expressed per unit of time. I will report annual values of these variables and parameters, and I will make adjustments to take account of the fact that a period is many years. Specifically, I will assume that a period in the model lasts for $N$ years. I will calculate the time preference discount factor $\delta$ as $\delta=(1+\nu)^{-N}$ where $\nu$ is the annual rate of time preference. Similarly, I will calculate the (gross) riskless interest rate per period $r$ as $r=\left(1+r_{a n n}\right)^{N}$ where $r_{a n n}$ is the (net) riskless interest rate per year. It will be convenient to define the following empirical values on a (net) annual basis: $\widehat{r}_{a n n} \equiv \widehat{r}^{-N}-1$ and $\widehat{\eta}_{a n n} \equiv \widehat{\eta}^{-N}-1$.

Converting the distribution of the (net) annual risky rate $R_{a n n, t}$ to a distribution of the risky rate per period $R_{t}$ involves an additional consideration. Suppose that the distribution of the annual risky rate is a twopoint distribution with $1+R_{a n n, t} \in\{\mu+\chi, \mu-\chi\}$. If the annual risky rate were perfectly serially correlated over the $N$ years of the period, then the (gross) risky rate per period would be a two-point distribution with $R_{t}$ $\in\left\{(\mu+\chi)^{N},(\mu-\chi)^{N}\right\}$. However, if the annual risky rate is not perfectly serially correlated, this two-point distribution would overstate the variance per $N$-year period. In fact, the presence of mean reversion in stock prices, equivalently, negative serial correlation in stock returns, suggests that even assuming that the annual risky rate is i.i.d. over time would overstate the variance per $\mathrm{N}$-year period. To allow for negative serial correlation in stock returns, I assume that (gross) annual risky returns follow a first-order twopoint Markov process with

$$
1+R_{a n n, t} \in\{\mu+\chi, \mu-\chi\} \text { and } \operatorname{Pr}\left\{R_{a n n, t+1}=R_{a n n, t}\right\}=1-\varphi .
$$


Under the Markov process in equation (45), the (gross) annual risky return $1+R_{a n n, t}$ has a mean equal to $\mu$, a standard deviation equal to $\chi$, and a first-order serial correlation equal to $1-2 \varphi$.

The accumulation of annual returns over an $N$-year period is used in the portfolio allocation decision of young consumers. As shown in equation (A.4) in Appendix A, the portfolio allocation decision involves the choice of $\gamma_{t+1}$ to maximize an expression containing

$$
E_{t}\left\{\left[\left(1-\gamma_{t+1}\right) r_{t+1}+\gamma_{t+1} R_{t+1}\right]^{1-\phi}\right\}
$$

where the (gross) returns, $r_{t+1}$ and $R_{t+1}$, are measured over an $N$-year period. Defining

$$
z_{a n n, t+j} \equiv\left[(1-\gamma)\left(1+r_{a n n}\right)+\gamma\left(1+R_{a n n, t+j}\right)\right]^{1-\phi}
$$

the expression in equation (46) can be written as $E_{t}\left\{\prod_{j=1}^{N} z_{a n n, t+j}\right\}$. If the annual risky return $R_{a n n, t}$ follows a two-point Markov process, then $z_{a n n, t}$ will also follow a two-point Markov process. Lemma 3 in Appendix E presents a simple method for computing $E_{t}\left\{\prod_{j=1}^{N} z_{a n n, t+j}\right\} .{ }^{25}$

Table 1 contains the baseline values of the parameters used to calibrate the constant growth path. I use the moments of the annual risky rate of return reported by Mehra and Prescott (1985) for the period 1889-1978. Specifically, I set $\mu$ equal to 1.0698 , which implies a $6.98 \%$ annual mean (net) risky return, and I set the standard deviation, $\chi$, equal to 0.1654 per year. Fama and French (1988) report that for return horizons of one year, the serial correlation of stock returns is negative but not significantly different from zero. The serial correlation of stock returns becomes significantly negative as the horizon is lengthened to 2 years and declines until the horizon is about 3 to 5 years. In order to capture this mean reversion in stock prices over longer periods, I specify an annual serial correlation of -0.1 which implies $\varphi=0.55$.

\footnotetext{
${ }^{25}$ An alternative approach to calibrate $N$-period returns would be to calculate the empirical moments of $N$-period returns. The approach I use in this paper is more flexible in that it allows $N$ to be changed easily. In the baseline calibration, $N=30$, and the sensitivity analysis reports results for $N=25$ and $N=35$.
} 


\begin{tabular}{|c|c|c|}
\hline \multicolumn{3}{|c|}{ Table 1: Baseline Calibration } \\
\hline \multicolumn{3}{|c|}{ "Risky Rate (annual) } \\
\hline mean, $\mu$ (gross return per yr.) 1.0698 & $\varphi($ serial corr. $=1-2 \varphi)$ & 0.55 \\
\hline std. dev., $\chi(\%$ per yr.) & number of yrs. per pd., $N$ & 30 \\
\hline \multicolumn{3}{|c|}{ Treasury Policy Function } \\
\hline gov't purch. parameter, $g$ & tax responsiveness, $\lambda$ & 0.1 \\
\hline tax parameter, $\tau$ & target bond ratio, $\beta$ & 0.25 \\
\hline \multicolumn{3}{|c|}{ Social Security Policy Function } \\
\hline riskless replacement rate, $\theta_{0}$ & target trust fund ratio, $\sigma$ & 0.035 \\
\hline risky replacement rate, $\theta_{1}$ & risky trust fund share, $\gamma_{S}$ & 0.0 \\
\hline \multicolumn{2}{|l|}{ share of capital in production function, $\alpha$} & 0.375 \\
\hline \multicolumn{3}{|c|}{ Empirical Moments to Fit } \\
\hline riskless rate, $\widehat{r}_{\text {ann }}(\%$ per yr.) & growth rate, $\widehat{\eta}_{a n n}(\%$ per yr.) & 1.3 \\
\hline \multicolumn{3}{|c|}{ Preference Parameter Values that Fit Empirical Moments } \\
\hline coeff. of rel. risk aversion, $\phi$ & time pref., $\nu$ (\% per yr.) & 0.6874 \\
\hline
\end{tabular}

Each period in the model represents half of an adult lifetime. More specifically, the first period of a person's life corresponds to time in the labor force, and the second period corresponds to retirement. I have chosen to set $N$, the number of years per period, equal to 30 , which is a compromise between the larger numbers of years in the workforce and the smaller number of years in retirement.

For the tax policy function, I have set the government purchases parameter $g$ and the tax parameter $\tau$ both equal to 0.2 which is the approximate share of government purchases in GDP in the United States. It is difficult to pin down the value of the tax responsiveness parameter $\lambda$, which is the fraction of the adjustment in the primary deficit that is achieved by changing taxes. Complete tax smoothing is represented by $\lambda=0$. I set $\lambda=0.1$ in the baseline simulation, and I explore the quantitative impact of $\lambda$ in Tables 2 and 3. I set the baseline value of the target bond-capital ratio, $\beta$, equal to 0.25 . In 1997, the ratio of Treasury debt held by the public and by the Social Security Trust Fund to the stock of fixed private capital was 0.254.

In the baseline calibration, I treat the benefits in the pay-as-you-go Social Security system in the United States as riskless. Thus, I set the risky replacement rate $\theta_{1}$ equal to zero. I set the riskless replacement rate $\theta_{0}$ equal to 0.15 . This value may seem low, but it is higher than the $12.4 \%$ 
Social Security tax rate, and it is almost twice as high as the ratio of Social Security benefits to compensation of employees in 1996 (which was 0.0787). ${ }^{26}$ In 1997, the Social Security Trust Fund was 3.6\% as large as the fixed private capital stock in the United States. I set the target value of the trust fundcapital ratio, $\sigma$, equal to 0.035 in the baseline. Since the Social Security Trust Fund is currently invested entirely in bonds, I set $\gamma_{S}=0$ in the baseline calibration.

Over the past half century in the United States, the share of labor income in GDP has averaged 0.625 with a standard deviation of only $0.009 .^{27}$ Since the labor share is $1-\alpha$, I set $\alpha=0.375$ in the baseline calibration.

I calibrate the model to match two empirical moments: the average riskless interest rate $\widehat{r}_{a n n}$, and the average growth rate of the capital stock $\widehat{\eta}_{a n n}$. For $\widehat{r}_{a n n}$, I use $0.8 \%$ per year, which is the average value of the riskless interest rate reported by Mehra and Prescott (1985) for the period 18891978. As for the growth rate of the capital, it is important to note that the population and the labor force are constant across generations in the model. Thus, the appropriate empirical counterpart of the growth rate of capital in the model is the empirical growth rate of the capital-labor ratio. Over the period 1947-1997, the fixed private capital stock in the United States grew by $3.17 \%$ per year and employment grew by $1.65 \%$ per year, implying that the capital-labor ratio grew by approximately $1.52 \%$ per year. However, over the shorter period 1967-1997, the annual growth of capital slowed to $2.90 \%$ per year and the growth rate of employment increased to $1.87 \%$ per year, so the growth rate of the capital-labor ratio declined (relative to the longer time period) to $1.03 \%$ per year. I will use an intermediate value of $1.3 \%$ per year for $\widehat{\eta}_{a n n}$.

The last row of Table 1 reports the values of the preference parameters for which the riskless interest rate $r$ and the growth rate of the capital stock $\eta$ calculated by the model match their empirical counterparts. Specifically, with a coefficient of relative risk aversion $\phi$ of 7.7577 and a rate of time preference $\nu$ of $0.6874 \%$ per year, the model matches the riskless interest rate and the growth rate of the capital stock. The values of these preference

\footnotetext{
${ }^{26}$ Of course, this ratio in 1996 significantly understates the replacement ratio because the large population of baby-boom workers means that the ratio of workers to retirees is temporarily (for a few decades) high.

${ }^{27}$ The labor share $\Lambda$ is computed as the solution of the following equation: $\frac{\text { compensation of employees }+\Lambda\left(\text { proprietors }^{\prime} \text { income }\right)}{G D P}=\Lambda$.
} 
parameters are quite plausible. ${ }^{28}$

Table 2 reports the results of a sensitivity analysis that varies one parameter at a time. Each row of the table reports two values of a parameter that differ from the baseline value, and also reports the implied (net) annual values of the riskless interest rate $r$ and the growth rate of capital $\eta$ along a constant growth path. For parameters that are not equal to zero in the baseline, Table 2 reports results for one value larger than in the baseline and one value smaller than in the baseline. For parameters that equal zero in the baseline, Table 2 reports results using two values larger than zero.

The most glaring result in Table 2 arises when $\mu$, the (gross) mean annual risky rate of return, is reduced to 1.05 , which is a $5 \%$ average annual (net) rate of return. In this case the model produces a riskless interest rate of $-1.18 \%$ per year and a growth rate of capital of $-0.62 \%$ per year. These results are far from their empirical counterparts. However, in judging the implications of these results for the empirical plausibility of the model, it is important to remember that the preference parameters $\phi$ and $\nu$ used in this calculation were calibrated under the assumption that the mean return $\mu$ is 1.0698. When $\mu=1.05$, the model can match the empirical values of $r$ and $\eta$ by using the following values for the preference parameters: $\phi=3.8186$ and $\nu=-1.35 \%$ per year. Although a coefficient of relative risk aversion of 3.8 is very reasonable, the negative rate of time preference is a bit curious. ${ }^{29}$

A primary issue motivating this paper is the impact of investing part of the Social Security Trust Fund in risky capital. The Social Security Trust Fund in the United States is currently invested entirely in riskless bonds, so I set $\gamma_{S}=0$ in the baseline calibration. The sensitivity analysis in Table 2 reports the results of increasing $\gamma_{S}$ to 0.15 and to 0.3 . The value of $\gamma_{S}$ that is considered in current policy discussions is about 0.15. Increasing $\gamma_{S}$ to 0.15 in the model increases the riskless interest rate to $0.82 \%$ per year (from $0.80 \%$ per year in the baseline) and increases the rate of growth of the capital stock to $1.32 \%$ per year (from $1.30 \%$ per year in the baseline). These

\footnotetext{
${ }^{28}$ The literature on the equity premium puzzle typically requires a coefficient of relative risk aversion $\phi$ well above 10 to match moments of asset returns. However, one should not regard the relatively low and reasonable value of 7.7577 for $\phi$ as a resolution of the equity premium puzzle because the model in the paper has not been calibrated to the variability of consumption.

${ }^{29}$ Setting the rate of time preference equal to zero and using a coefficient of relative risk aversion $\phi$ equal to 3.8186 implies $r_{a n n}=0.80 \%$ per year and $\eta_{a n n}=0.51 \%$ per year, when $\mu=1.05$.
} 


\begin{tabular}{|c|c|c|c|c|c|c|}
\hline \multicolumn{7}{|c|}{$\begin{array}{lll}\text { Table 2. } & \text { Sensitivity Analysis: } & \text { Changing One Parameter at a Time }\end{array}$} \\
\hline Parameter & $\begin{array}{c}\text { Parameter } \\
\text { Value }\end{array}$ & $\begin{array}{l}r_{a n n} \\
\% \text { per }\end{array}$ & $\begin{array}{l}\eta_{\text {ann }} \\
\text { year }\end{array}$ & $\begin{array}{c}\text { Parameter } \\
\text { Value }\end{array}$ & $\begin{array}{l}r_{a n n} \\
\% \text { per }\end{array}$ & $\begin{array}{c}\eta_{\text {ann }} \\
\text { year }\end{array}$ \\
\hline$\mu$ & 1.05 & -1.18 & -0.62 & 1.09 & 2.82 & 3.26 \\
\hline$\chi$ & 0.12 & 2.75 & 1.96 & 0.22 & -1.01 & 0.44 \\
\hline$\varphi$ & 0.5 & 0.32 & 1.10 & 0.6 & 1.28 & 1.48 \\
\hline$N$ & 25 & 0.27 & 0.55 & 35 & 1.25 & 1.84 \\
\hline$\theta_{0}$ & 0.10 & 0.14 & 1.87 & 0.20 & 1.27 & 0.76 \\
\hline$\theta_{1}$ & 0.05 & 0.65 & 0.83 & 0.10 & 0.51 & 0.34 \\
\hline$\sigma$ & 0.01 & 0.83 & 1.27 & 0.06 & 0.77 & 1.33 \\
\hline$\gamma_{S}$ & 0.15 & 0.82 & 1.32 & 0.30 & 0.83 & 1.35 \\
\hline$g$ & 0.15 & 0.80 & 1.35 & 0.25 & 0.80 & 1.25 \\
\hline$\tau$ & 0.15 & 0.80 & 1.73 & 0.25 & 0.80 & 0.81 \\
\hline$\lambda$ & 0.0 & 0.80 & 1.30 & 0.2 & 0.80 & 1.30 \\
\hline$\beta$ & 0.20 & 0.75 & 1.36 & 0.30 & 0.85 & 1.24 \\
\hline$\alpha$ & 0.32 & 1.20 & 2.11 & 0.43 & 0.43 & 0.48 \\
\hline $\bar{\phi}$ & 4.00 & 2.68 & 1.94 & 10.00 & 0.05 & 0.97 \\
\hline$\nu(\%$ per yr.) & 0.0 & 0.80 & 1.79 & 1.40 & 0.80 & 0.77 \\
\hline
\end{tabular}

effects are small because the Social Security Trust Fund is small relative to the capital stock. ${ }^{30}$

Along a constant growth path, the ratio of the Social Security Trust Fund to the capital stock equals its target value $\sigma$. The small value of $\sigma$ used in the calculations reported above was chosen to match the current value of the ratio of the Social Security Trust Fund to the capital stock in the United States. However, the Trust Fund is projected to grow substantially over the next several years reaching a peak value in the year 2016 that is 2.6 times as large as its current value. ${ }^{31}$ Indeed, it is the prospect of a large trust fund

\footnotetext{
${ }^{30}$ Formally, applying the implicit function theorem to equations (C.3) and (C.5) in Appendix $\mathrm{C}$ along a constant growth path implies $\frac{\partial r}{\partial \gamma_{S}}=$ $-\frac{\sigma}{\gamma^{\prime}(r)\left(1+\beta-\sigma+\frac{\theta_{0}(1-\alpha) \bar{A}}{r}+\theta_{1} \frac{1-\alpha}{\alpha}\right)-\gamma(r) \frac{\theta_{0}(1-\alpha) \bar{A}}{r^{2}}}$, so that $\lim _{\sigma \rightarrow 0} \frac{\partial r}{\partial \gamma_{S}}=0$. Thus, when the trust fund-capital ratio $\sigma$ is small, the effect of $\gamma_{S}$ on the interest rate is small. The proof of Proposition 5 indicates that $\frac{\partial \eta}{\partial \gamma_{S}}$ is the sum of a term that is proportional to $\sigma$ and a term that is proportional to $\frac{\partial r}{\partial \gamma_{S}}$. Thus $\frac{\partial \eta}{\partial \gamma_{S}}$ will be small if $\sigma$ is small.

${ }^{31}$ This projection, which is taken from the Board of Trustees of the OASDI Trust Funds (1998), is based on the assumption that the Trust Fund is invested entirely in bonds. If
} 


\begin{tabular}{||c|c|c|c||}
\hline \hline \multicolumn{2}{||c||}{ Table 3. Risky Trust Fund When $\sigma=0.14$} \\
\cline { 2 - 4 } & $\gamma_{S}=0.0$ & $\gamma_{S}=0.15$ & $\gamma_{S}=0.30$ \\
\hline$r_{a n n}(\%$ per yr. $)$ & 0.69 & 0.75 & 0.81 \\
\hline$\eta_{a n n}(\%$ per yr. $)$ & 1.41 & 1.51 & 1.60 \\
\hline \hline \multirow{3}{*}{} & \multicolumn{3}{|c||}{$\lambda=0.9$} \\
\cline { 2 - 4 } & $\gamma_{S}=0.0$ & $\gamma_{S}=0.15$ & $\gamma_{S}=0.30$ \\
\hline$r_{\text {ann }}(\%$ per yr. $)$ & 0.69 & 0.75 & 0.81 \\
\hline$\eta_{a n n}(\%$ per yr. $)$ & 1.44 & 1.54 & 1.63 \\
\hline \hline
\end{tabular}

that has fueled interest in investing part of the trust fund in equities. Table 3 presents the effects of investing part of the trust fund in risky capital along a constant growth path with $\sigma=0.14$, which is four times as high as in the baseline calculations. Even with this much larger trust fund, investing $15 \%$ of the trust fund in risky capital has only modest effects on the riskless interest rate and the growth rate of capital. The riskless interest rate increases by only 6 basis points, and the growth rate of the capital stock increases by one tenth of one percent per year.

The baseline calibration in Table 1 is based on a value of $\lambda=0.1$. However, the value of $\lambda$, which measures the responsiveness of taxes to changes in the primary deficit needed to satisfy the Treasury policy function, is not well determined. In principle, it could be anywhere between 0 and 1 . Recall that the sufficient condition in Proposition 6 for an increase in $\gamma_{S}$ to increase $\eta$ depends on the value of $\lambda$. A higher value of $\lambda$ makes this condition less likely to hold. To see whether a higher value of $\lambda$ can violate this condition, suppose that $\lambda=1$, which is its maximum admissable value. In this case, the sufficient condition in Proposition 6 is $\delta\left[\left(1-\gamma_{S}\right) \sigma-\beta\right]+\eta \frac{\theta_{0}(1-\alpha) \bar{A}}{r^{2}} \geq 0$. In the baseline calculation, $\delta\left[\left(1-\gamma_{S}\right) \sigma-\beta\right]=-0.175$ and $\eta \frac{\theta_{0}(1-\alpha) \bar{A}}{r^{2}}=1.729$, so the sufficient condition in Proposition 6 is satisfied by a wide margin even when $\lambda=1$. Thus, for any allowable value of $\lambda$, an increase in $\gamma_{S}$ increases $\eta$, the growth rate of the capital stock along a constant growth path.

In addition, $\lambda$ has very small impact on the calculated responses of the interest rate and growth rate of capital to a change in $\gamma_{S}$. The top panel of Table 3 reports the values of the riskless interest rate and the growth

the Trust Fund earns a higher rate of return by investing in risky capital, then it would reach an even larger value. 
rate of capital when $\lambda=0.1$, and the bottom panel reports the results for $\lambda=0.9$. The values of the riskless interest rate are identical in the top and bottom panels because the equilibrium condition for the riskless interest rate in equation (41) is independent of $\lambda$. Although the growth rate capital is not independent of $\lambda$, the growth rates differ by only 3 basis points when $\lambda$ increases from 0.1 to $0.9 .^{32}$

\section{Concluding Remarks}

I have shown that shifting some of the assets of the Social Security Trust Fund from bonds to risky capital increases the growth rate of the capital stock in the following period and along a constant growth path. This finding is virtually the opposite of the result in Abel (1998) where I show that such a portfolio shift of the Social Security Trust Fund reduces the amount of capital accumulation in the following period. Although there are various modelling differences between the two papers, the fundamental reason for the apparent difference in results is that the earlier paper analyzes a definedcontribution Social Security system and the current paper analyzes a definedbenefit Social Security system. ${ }^{33}$ In both papers, when the Social Security Trust Fund moves into risky capital, the expected income of the trust fund increases, and this increase in expected income is passed along to individuals. In a defined-contribution system, a natural policy experiment is to hold the contribution fixed and thus the gains from increased trust fund earnings accrue to individuals as increased retirement benefits when they are old. In

${ }^{32}$ Since $\delta\left[\left(1-\gamma_{S}\right) \sigma-\beta\right]+\eta \frac{\theta_{0}(1-\alpha) \bar{A}}{r^{2}}$ is an increasing function of $\sigma$ (provided that the Trust Fund is not entirely invested in risky capital), the sufficient condition holds for higher values of $\sigma$, such as $\sigma=0.14$, as in Table 3 .

${ }^{33}$ There is also a major modelling difference between the two papers. In the current paper, which examines a defined-benefit Social Security system, all individuals in a given cohort are identical, and they all hold portfolios with both bonds and risky capital. As shown analytically in footnotes 14 and 19, a change in the portfolio of a definedcontribution Social Security system would have no effect on the riskless interest rate or growth rate of capital in this sort of model because individuals would offset the effects of changes in the Social Security Trust Fund's portfolio by changing their own portfolios. The previous paper, which analyzes a defined-contribution system introduces intra-cohort heterogeneity of earnings and fixed costs of investing in risky capital so that low-income individuals will not hold any risky capital directly in their portfolios. With this modification, changes in the portfolio of the Social Security Trust Fund are no longer neutral, even in a defined-contribution system. 
response to increased retirement benefits, young consumers increase their current consumption and thus reduce capital accumulation. In a definedbenefit system, a natural policy experiment is to hold the benefit fixed and thus the gains from increased trust fund earnings accrue to individuals in the form of lower taxes when they are young. In response to increased disposable income when young, consumers increase their saving when they are young, and thus capital accumulation increases.

Confining attention to defined-benefit Social Security systems, and holding Social Security benefits fixed as analyzed in the current paper, it might appear that the Social Security Trust Fund should invest in risky capital because this change in its portfolio allocation will increase the growth rate of the capital stock. However, there are still several questions that future research must address, even in the context of this model, to reach a strong policy recommendation about the allocation of the assets in the Social Security Trust Fund. First, the results about the effect on the growth rate of the capital stock are confined to constant growth paths along which all shocks take on their mean values. Of course, one of the concerns about investing some of the Social Security Trust Fund in risky capital is the risk that the rate of return may turn out to be very low. A normative welfare analysis would have to take account of the entire distribution of outcomes. In addition, a normative analysis would have to recognize that government purchases in this model are endogenous. To the extent that individuals obtain utility from government purchases, I have assumed that any utility from government purchases is additively separable from the utility of private consumption. Although this assumption is sufficient to analyze optimal private behavior and competitive equilibria, it does not address the welfare consequences of endogenous changes in the level of government purchases.

Intergenerational risk-sharing is another important aspect of the welfare analysis of various Social Security policies. Bohn (1998b) analyzes the intergenerational sharing of various risks in considering the effects of including equities in the Social Security Trust Fund. While the framework I have developed in this paper focuses on a narrower set of risks, it suggests the possibility of additional channels to share risks intergenerationally by allowing the Treasury's debt-capital ratio and the Social Security Trust Fund-capital ratio to vary across time and across generations in response to shocks. The various $\rho_{i}$ parameters $(i=A, B, R, S)$ reflect opportunities to share risks across time and across generations. Exploration of these opportunities is left for future research. 


\section{A The Consumption and Portfolio Decision of An Individual}

Using the definitions of $\Omega_{t}, a_{t+1}$, and $\gamma_{t+1}$ in equations (11), (12), and (14) respectively, it is convenient to rewrite the expression for consumption when young in equation (6) as

$$
C_{t}=\Omega_{t}-a_{t+1}
$$

and consumption when old in equation (9) as

$$
X_{t+1}=\left[\left(1-\gamma_{t+1}\right) r_{t+1}+\gamma_{t+1} R_{t+1}\right] a_{t+1} .
$$

The consumer's optimization problem can be rewritten by substituting equations (A.1) and (A.2) into equation (10) to obtain

$$
\max _{a_{t+1}, \gamma_{t+1}} \ln \left(\Omega_{t}-a_{t+1}\right)+\delta \ln a_{t+1}+\delta \psi\left(\gamma_{t+1}, r_{t+1}\right)
$$

where $^{34}$

$$
\psi\left(\gamma_{t+1}, r_{t+1}\right) \equiv \frac{1}{1-\phi} \ln E_{t}\left\{\left[\left(1-\gamma_{t+1}\right) r_{t+1}+\gamma_{t+1} R_{t+1}\right]^{1-\phi}\right\} \text { if } 0<\phi \neq 1 .
$$

The optimal level of saving and consumption is determined by differentiating the maximand in equation (A.3) with respect to $a_{t+1}$ and setting the derivative equal to zero to obtain

$$
a_{t+1}=\frac{\delta}{1+\delta} \Omega_{t} .
$$

The portfolio allocation problem is solved by differentiating $\psi\left(\gamma_{t+1}, r_{t+1}\right)$ with respect $\gamma_{t+1}$ and setting the derivative equal to zero to obtain

$$
E_{t}\left\{\left[\left(1-\gamma_{t+1}\right) r_{t+1}+\gamma_{t+1} R_{t+1}\right]^{-\phi}\left(R_{t+1}-r_{t+1}\right)\right\}=0 .
$$

Equation (A.6) implicitly defines the optimal value of $\gamma_{t+1}$, which is the share of an individual's total portfolio devoted to risky assets. This equation holds for any $\phi>0$, including the case of logarithmic utility, $\phi=1$.

Let $\gamma\left(r_{t+1}\right)$ be the value of $\gamma_{t+1}$ that solves equation (A.6). Appendix B derives the properties of $\gamma\left(r_{t+1}\right)$.

\footnotetext{
${ }^{34}$ If $\phi=1, \psi\left(\gamma_{t+1}, r_{t+1}\right) \equiv E_{t}\left\{\ln \left[\left(1-\gamma_{t+1}\right) r_{t+1}+\gamma_{t+1} R_{t+1}\right]\right\}$.
} 


\section{B Properties of $\gamma(r)$}

If $E_{t}\left\{R_{t+1}\right\}-r_{t+1}=0$, then $E_{t}\left\{r_{t+1}^{-\phi}\left(R_{t+1}-r_{t+1}\right)\right\}=0$, which implies that $\gamma_{t+1}=0$ satisfies equation (A.6). Therefore, if $E_{t}\left\{R_{t+1}\right\}-r_{t+1}=0$, the optimal value of $\gamma_{t+1}$ is zero, so

$$
\gamma\left(E_{t}\left\{R_{t+1}\right\}\right)=0
$$

As the gross riskless interest rate, $r_{t+1}$, approaches $R_{L} \equiv \alpha A_{L}$ from above, the optimal value of $\gamma_{t+1}$ becomes arbitrarily large. That is,

$$
\lim _{r_{t+1 \downarrow R_{L}}} \gamma\left(r_{t+1}\right)=\infty
$$

To analyze the derivative of $\gamma\left(r_{t+1}\right)$ with respect to $r_{t+1}$, define

$$
F(\gamma, r, \phi) \equiv E\left\{x^{-\phi}(R-r)\right\}
$$

where $^{35} x \equiv r+\gamma(R-r)>0$ and $r \geq R_{L}$. Observe from equation (A.6) that the optimal value of $\gamma, \gamma^{*}$, solves

$$
F\left(\gamma^{*}, r, \phi\right)=0
$$

Differentiating equation (B.3) with respect to $\gamma$ yields

$$
F_{\gamma}(\gamma, r, \phi)=-\phi E\left\{x^{-\phi-1}(R-r)^{2}\right\}<0
$$

Since $F_{\gamma}(\gamma, r, \phi)<0$, there is a unique value of $\gamma$ that solves $F(\gamma, r, \phi)=$ 0 for given values of $r$ and $\phi$.

The response of $\gamma^{*}$ to a change in $r$ is given by $\gamma^{\prime}(r)=\frac{d \gamma^{*}}{d r}=-\frac{F_{r}\left(\gamma^{*}, r, \phi\right)}{F_{\gamma}\left(\gamma^{*}, r, \phi\right)}$. Since $F_{\gamma}\left(\gamma^{*}, r, \phi\right)<0$, the sign of $\gamma^{\prime}(r)$ is the same as the sign of $F_{r}\left(\gamma^{*}, r, \phi\right)$. Differentiating equation (B.3) with respect to $r$ yields

$$
F_{r}(\gamma, r, \phi)=E\left\{-\phi x^{-\phi-1}(1-\gamma)(R-r)-x^{-\phi}\right\} .
$$

\footnotetext{
${ }^{35}$ Both $r$ and $R$ are assumed to be positive. I restrict attention to values of $\gamma$ for which $x>0$ because optimality requires that $\operatorname{Pr}\{x>0\}=1$.
} 
Use the fact that $R-x=(1-\gamma)(R-r)$ to rewrite equation (B.6) as

$$
F_{r}(\gamma, r, \phi)=E\left\{-\phi x^{-\phi-1} R+(\phi-1) x^{-\phi}\right\}
$$

Inspection of equation (B.7) reveals that if $\phi \leq 1$, then $F_{r}(\gamma, r, \phi)<0$ and hence $\gamma^{\prime}(r)<0$. In the case with $\phi>1$, there is no general result for the sign of $\gamma^{\prime}(r)$. Even when the distribution of $R$ is a symmetric two-point distribution, the sign of $\gamma^{\prime}(r)$ is not determinate.

To determine the effect of a change in the coefficient of relative risk aversion $\phi$, differentiate $F(\gamma, r, \phi)$ with respect to $\phi$ to obtain

$$
F_{\phi}(\gamma, r, \phi)=-E\left\{x^{-\phi}(R-r) \ln x\right\} .
$$

If $R-r<0$, then $\ln x<\ln r$, provided that $\gamma>0$. Therefore, if $R-r<0$, then $x^{-\phi}(R-r) \ln x>x^{-\phi}(R-r) \ln r$. Similarly, if $R-r>0$, then $\ln x>$ $\ln r$, provided that $\gamma>0$. Therefore, if $R-r>0$, then $x^{-\phi}(R-r) \ln x>$ $x^{-\phi}(R-r) \ln r$. Thus, if the optimal value $\gamma^{*}$ is positive, then when $\gamma=\gamma^{*},{ }^{36}$

$$
E\left\{x^{-\phi}(R-r) \ln x\right\}>E\left\{x^{-\phi}(R-r) \ln r\right\}=0 .
$$

Substituting equation (B.9) into equation (B.8) yields

$$
F_{\phi}(\gamma, r, \phi)<0 \text {. }
$$

Therefore, since $F_{\gamma}(\gamma, r, \phi)<0$,

$$
\frac{d \gamma^{*}}{d \phi}<0
$$

which means that an increase in the coefficient of relative risk aversion $\phi$ leads to a reduction in $\gamma$, the share of the portfolio devoted to the risky asset.

\section{Proof of Proposition 2}

Define the function $f\left(r_{t+1}, b_{t+1}, s_{t+1}, \gamma_{S, t+1}, \theta_{0}, \theta_{1}\right)$ as the right-hand side of equation (33). This function is continuous in $r_{t+1}$ for $\alpha A_{L} \equiv R_{L}<r_{t+1} \leq$ $\bar{R} \equiv E_{t}\left\{R_{t+1}\right\}$. Equation (B.1) and the condition in equation (31) imply

$$
f\left(E_{t}\left\{R_{t+1}\right\}, b_{t+1}, s_{t+1}, \gamma_{S, t+1}, \theta_{0}, \theta_{1}\right)<0 .
$$

\footnotetext{
${ }^{36} \mathrm{I}$ am assuming that the distribution of $R$ is nondegenerate so that $\operatorname{Pr}\{R \neq r\}>0$.
} 
Equation (B.2) and the condition in equation (30) imply

$$
\lim _{r_{t+1 \downarrow R_{L}}} f\left(r_{t+1}, b_{t+1}, s_{t+1}, \gamma_{S, t+1}, \theta_{0}, \theta_{1}\right)=\infty .
$$

Equations (C.1) and (C.2) and the fact that $f\left(r_{t+1}, b_{t+1}, s_{t+1}, \gamma_{S, t+1}, \theta_{0}, \theta_{1}\right)$ is continuous in $r_{t+1}$ for $r_{t+1} \in\left(R_{L}, \bar{R}\right.$ imply that there is at least one value of $r_{t+1} \in\left(R_{L}, \bar{R}\right]$ for which $f\left(r_{t+1}, b_{t+1}, s_{t+1}, \gamma_{S, t+1}, \theta_{0}, \theta_{1}\right)=0$.

To prove that the equilibrium value of $r_{t+1}$ is unique, differentiate $f\left(r_{t+1}, b_{t+1}, s_{t+1}, \gamma_{S, t+1}, \theta_{0}, \theta_{1}\right)$ with respect to $r_{t+1}$ and use the assumption in Proposition 2 that $\gamma^{\prime}\left(r_{t+1}\right)<0$ to obtain

$$
\begin{array}{r}
\frac{\partial f}{\partial r_{t+1}}=\gamma^{\prime}\left(r_{t+1}\right)\left(1+b_{t+1}-s_{t+1}+\frac{\theta_{0}(1-\alpha) \bar{A}}{r_{t+1}}+\theta_{1} \frac{1-\alpha}{\alpha}\right) \\
-\gamma\left(r_{t+1}\right) \frac{\theta_{0}(1-\alpha) \bar{A}}{r_{t+1}^{2}}<0 .
\end{array}
$$

Since $\frac{\partial f}{\partial r_{t+1}}<0$, the value of $r_{t+1}$ for which $f\left(r_{t+1}, b_{t+1}, s_{t+1}, \gamma_{S, t+1}, \theta_{0}, \theta_{1}\right)=$ 0 is unique.

To analyze the effects of various variables on the riskless interest rate, compute the following partial derivatives

$$
\begin{gathered}
\frac{\partial f}{\partial b_{t+1}}=\gamma\left(r_{t+1}\right)>0 \\
\frac{\partial f}{\partial \gamma_{S, t+1}}=s_{t+1} \\
\frac{\partial f}{\partial s_{t+1}}=\gamma_{S, t+1}-\gamma\left(r_{t+1}\right) \\
\frac{\partial f}{\partial \theta_{0}}=\gamma\left(r_{t+1}\right) \frac{(1-\alpha) \bar{A}}{r_{t+1}}>0
\end{gathered}
$$




$$
\frac{\partial f}{\partial \theta_{1}}=-\frac{1-\alpha}{\alpha}\left(1-\gamma\left(r_{t+1}\right)\right)<0
$$

where the inequalities in equations (C.4), (C.7), and (C.8) follow from Proposition 1.

The implicit function theorem implies that $\frac{\partial r\left(b_{t+1}, s_{t+1}, \gamma_{S, t+1}, \theta_{0}, \theta_{1}\right)}{\partial z}=-\frac{\partial f / \partial z}{\partial f / \partial r_{t+1}}$ where $z \in\left\{b_{t+1}, s_{t+1}, \gamma_{S, t+1}, \theta_{0}, \theta_{1}\right\}$. Therefore, $\operatorname{sign}\left(\frac{\partial r\left(b_{t+1}, s_{t+1}, \gamma_{S, t+1}, \theta_{0}, \theta_{1}\right)}{\partial z}\right)=\operatorname{sign}\left(\frac{\partial f}{\partial z}\right)$. q.e.d.

\section{Derivation of the Growth Rate of the Cap- ital Stock}

Substitute equation (36) into equation (35), use the definitions $b_{t+1} \equiv \frac{B_{t+1}}{K_{t+1}}$ and $s_{t+1} \equiv \frac{S_{t+1}}{K_{t+1}}$, and multiply both sides of the resulting equation by $1+\delta$ to obtain

$$
\begin{aligned}
(1+\delta)\left(b_{t+1}+1-s_{t+1}\right) K_{t+1}= & \delta\left(w_{t}-T_{t}^{T}-T_{t}^{S}\right) \\
& -\left(\frac{\theta_{0}(1-\alpha) \bar{A}}{r_{t+1}}+\theta_{1} \frac{1-\alpha}{\alpha}\right) K_{t+1} .
\end{aligned}
$$

The amount of Social Security taxes can be rewritten by substituting equation (24) into equation (27) to obtain

$$
\begin{aligned}
T_{t}^{S}= & {\left[\sigma+\rho_{S}\left(s_{t}-\sigma\right)+\rho_{R}\left(R_{t}-\bar{R}\right) \gamma_{S, t} s_{t}\right] K_{t+1} } \\
& +Q_{t}-\left[\left(1-\gamma_{S, t}\right) r_{t}+\gamma_{S, t} R_{t}\right] s_{t} K_{t}
\end{aligned}
$$

Use equation (7) to substitute for $Q_{t}$ in equation (D.2) to obtain

$$
T_{t}^{S}=\Phi\left(T_{t}^{S}, K_{t+1}\right) K_{t+1}+\Phi\left(T_{t}^{S}, K_{t}\right) K_{t}
$$


where

$$
\Phi\left(T_{t}^{S}, K_{t+1}\right) \equiv \sigma+\rho_{S}\left(s_{t}-\sigma\right)+\rho_{R}\left(R_{t}-\bar{R}\right) \gamma_{S, t} s_{t}
$$

and

$$
\Phi\left(T_{t}^{S}, K_{t}\right) \equiv\left(\theta_{0} \bar{A}+\theta_{1} A_{t}\right)(1-\alpha)-\left[\left(1-\gamma_{S, t}\right) r_{t}+\gamma_{S, t} R_{t}\right] s_{t}
$$

Now rewrite the Treasury's tax revenue in equation (23) as

$$
T_{t}^{T}=\Phi\left(T_{t}^{T}, K_{t+1}\right) K_{t+1}+\Phi\left(T_{t}^{T}, K_{t}\right) K_{t}
$$

where

$$
\Phi\left(T_{t}^{T}, K_{t+1}\right) \equiv-\lambda\left[\beta+\rho_{B}\left(b_{t}-\beta\right)+\rho_{A}(g-\tau)\left(A_{t}-\bar{A}\right)\right]
$$

and

$$
\Phi\left(T_{t}^{T}, K_{t}\right) \equiv[(1-\lambda) \tau+\lambda g] A_{t}+\lambda r_{t} b_{t}
$$

Substitute equations (D.3) and (D.6) into equation (D.1) and use equation (4) to obtain

$$
\begin{aligned}
& {\left[\begin{array}{c}
(1+\delta)\left(b_{t+1}+1-s_{t+1}\right) \\
+\frac{\theta_{0}(1-\alpha) \bar{A}}{r_{t+1}}+\theta_{1} \frac{1-\alpha}{\alpha}
\end{array}\right] K_{t+1} } \\
= & \delta\left(\begin{array}{c}
(1-\alpha) A_{t} K_{t}-\Phi\left(T_{t}^{S}, K_{t+1}\right) K_{t+1}-\Phi\left(T_{t}^{S}, K_{t}\right) K_{t} \\
-\Phi\left(T_{t}^{T}, K_{t+1}\right) K_{t+1}-\Phi\left(T_{t}^{T}, K_{t}\right) K_{t}
\end{array}\right)
\end{aligned}
$$


Now use the definitions in equations (D.4), (D.5), (D.7), and (D.8), to rewrite equation (D.9) as

$$
H_{1} K_{t+1}=H_{0} K_{t}
$$

where

$$
H_{1} \equiv\left[\begin{array}{c}
(1+\delta)\left(1+b_{t+1}-s_{t+1}\right)+\frac{\theta_{0}(1-\alpha) \bar{A}}{r_{t+1}}+\theta_{1} \frac{1-\alpha}{\alpha} \\
+\delta\left[\sigma+\rho_{S}\left(s_{t}-\sigma\right)+\rho_{R}\left(R_{t}-\bar{R}\right) \gamma_{S, t} s_{t}\right] \\
-\delta \lambda\left[\beta+\rho_{B}\left(b_{t}-\beta\right)+\rho_{A}(g-\tau)\left(A_{t}-\bar{A}\right)\right]
\end{array}\right]
$$

and

$$
H_{0} \equiv \delta\left(\begin{array}{c}
{[1-\alpha-(1-\lambda) \tau-\lambda g] A_{t}-(1-\alpha)\left(\theta_{0} \bar{A}+\theta_{1} A_{t}\right)} \\
+\left[\left(1-\gamma_{S, t}\right) r_{t}+\gamma_{S, t} R_{t}\right] s_{t}-\lambda r_{t} b_{t}
\end{array}\right) .
$$

Rewrite the expression for $H_{1}$ by substituting the Treasury policy function from equation (18) and the Social Security policy function from equation (26) into equation (D.11) to obtain

$$
H_{1} \equiv\left[\begin{array}{c}
1+\delta+(1+\delta-\delta \lambda)\left[\beta+\rho_{B}\left(b_{t}-\beta\right)+\rho_{A}(g-\tau)\left(A_{t}-\bar{A}\right)\right] \\
-\left[\sigma+\rho_{S}\left(s_{t}-\sigma\right)+\rho_{R}\left(R_{t}-\bar{R}\right) \gamma_{S, t} s_{t}\right]+\frac{\theta_{0}(1-\alpha) \bar{A}}{r_{t+1}}+\theta_{1} \frac{1-\alpha}{\alpha}
\end{array}\right] .
$$

\section{E The Expectation of Multi-year Returns}

Lemma 3 Let $z_{t} \in\{Z(1), \ldots, Z(J)\}$ and define the transition probabilities $p(i, j) \equiv \operatorname{Pr}\left\{z_{t+1}=Z(j) \mid z_{t}=Z(i)\right\}$ and unconditional probabilities $\pi(j) \equiv$ $\operatorname{Pr}\left\{z_{t}=Z(j)\right\}$. If $\Pi^{\prime} \equiv[\pi(1), \ldots, \pi(J)], M$ is the $J \times J$ matrix with $(i, j)$ element $m(i, j) \equiv p(i, j) Z(j)$, and $\mathbf{i}$ is an $J \times 1$ vector of ones, then $E\left\{z_{t+1} \cdots z_{t+N}\right\}=\Pi^{\prime}\left(M^{N}\right) i$. 
Proof:

$$
\begin{aligned}
& E\left\{z_{t+1} \cdots z_{t+N} \mid z_{t}=Z(i)\right\} \\
= & \sum_{j_{1}, \cdots, j_{N}}\left[p\left(i, j_{1}\right) p\left(j_{1}, j_{2}\right) \cdots p\left(j_{N-1}, j_{N}\right)\right]\left[Z\left(j_{1}\right) Z\left(j_{2}\right) \cdots Z\left(j_{N}\right)\right]
\end{aligned}
$$

Use the definition $m(i, j) \equiv p(i, j) Z(j)$ to rewrite the conditional expectation as

$$
E\left\{z_{t+1} \cdots z_{t+N} \mid z_{t}=Z(i)\right\}=\sum_{j_{1}, \cdots, j_{N}} m\left(i, j_{1}\right) m\left(j_{1}, j_{2}\right) \cdots m\left(j_{N-1}, j_{N}\right) .
$$

Define

$$
y(N, i, j) \equiv \sum_{j_{1}, \cdots, j_{N-1}} m\left(i, j_{1}\right) m\left(j_{1}, j_{2}\right) \cdots m\left(j_{N-1}, j\right) .
$$

Equations (E.2) and (E.3) imply

$$
E\left\{z_{t+1} \cdots z_{t+N} \mid z_{t}=Z(i)\right\}=\sum_{j} y(N, i, j)
$$

The unconditional expectation is

$$
E\left\{z_{t+1} \cdots z_{t+N}\right\}=\sum_{i, j} \pi(i) y(N, i, j)
$$

Observe from equation (E.3) that

$y(N+1, i, k)=\sum_{j} \sum_{j_{1}, \cdots, j_{N-1}} m\left(i, j_{1}\right) m\left(j_{1}, j_{2}\right) \cdots m\left(j_{N-1}, j\right) m(j, k)$.

Equations (E.3) and (E.6) imply

$$
y(N+1, i, k)=\sum_{j} y(N, i, j) m(j, k) .
$$


Rewrite equation (E.7) in matrix form as

$$
Y_{N+1}=Y_{N} M
$$

where the $(i, j)$ element of $Y_{N+1}$ is $y(N+1, i, j)$ and the $(i, j)$ element of $Y_{N}$ is $y(N, i, j)$.

The solution of the matrix difference equation in (E.8) is

$$
Y_{N}=M^{N} .
$$

Therefore, the definition of $Y_{N}$ and equations (E.5) and (E.9) imply

$$
E\left\{z_{t+1} \cdots z_{t+N}\right\}=\sum_{i, j} \pi(i) y(N, i, j)=\Pi^{\prime}\left(M^{N}\right) \mathbf{i} .
$$




\section{References}

[1] Abel, Andrew B., "The Aggregate Effects of Including Equities in the Social Security Trust Fund, July 1998, revised August 1998.

[2] Board of Trustees of the Federal Old-Age and Survivors Insurance and Disability Insurance Trust Funds, 1998 Annual Report.

[3] Bohn, Henning, "Risk Sharing in a Stochastic Overlapping Generations Economy," mimeo, Department of Economics, University of California at Santa Barbara, November 1998.(a)

[4] Bohn, Henning, "Should the Social Security Trust Fund Hold Equities? An Intergenerational Welfare Analysis," mimeo, Department of Economics, University of California at Santa Barbara, November 1998.(b)

[5] Barro, Robert J. and Xavier Sala-i-Martin, Economic Growth (New York: McGraw-Hill, Inc.) 1995.

[6] Blanchard, Olivier J. and Stanley Fischer, Lectures on Macroeconomics (Cambridge, MA: MIT Press) 1989.

[7] Diamond, Peter A., "National Debt in a Neoclassical Growth Model," American Economic Review, 55, 5 (December 1965), 1126-1150.

[8] Epstein, Larry G. and Stanley E. Zin, "Substitution, Risk Aversion, and the Temporal Behavior of Consumption and Asset Returns: A Theoretical Framework," Econometrica, 57, 4 (July 1989), 937-970.

[9] Mehra, Rajnish and Edward C. Prescott, "The Equity Premium: A Puzzle," Journal of Monetary Economics, 15, 2 (March 1985), 145-161.

[10] Fama, Eugene F. and Kenneth R. French, "Permanent and Temporary Components of Stock Prices," Journal of Political Economy, 96, 2 (April 1988), 246-273.

[11] Weil, Philippe, "Nonexpected Utility in Macroeconomics," Quarterly Journal of Economics, 105, 1 (February 1990), 29-42. 